\title{
Hybrid Wing Body Aircraft System Noise Assessment With Propulsion Airframe Aeroacoustic Experiments
}

\author{
Russell H. Thomas ${ }^{*}$, Casey L. Burley ${ }^{\dagger}$ and Erik D. Olson ${ }^{*}$ \\ NASA Langley Research Center, Hampton, VA 23681 USA
}

\begin{abstract}
A system noise assessment of a hybrid wing body configuration was performed using NASA's best available aircraft models, engine model, and system noise assessment method. A propulsion airframe aeroacoustic effects experimental database for key noise sources and interaction effects was used to provide data directly in the noise assessment where prediction methods are inadequate. NASA engine and aircraft system models were created to define the hybrid wing body aircraft concept as a twin engine aircraft with a 7500 nautical mile mission. The engines were modeled as existing technology high bypass ratio turbofans. The baseline hybrid wing body aircraft was assessed at $22 \mathrm{~dB}$ cumulative below the FAA Stage 4 certification level. To determine the potential for noise reduction with relatively near term technologies, seven other configurations were assessed beginning with moving the engines two fan nozzle diameters upstream of the trailing edge and then adding technologies for reduction of the highest noise sources. Aft radiated noise was expected to be the most challenging to reduce and, therefore, the experimental database focused on jet nozzle and pylon configurations that could reduce jet noise through a combination of source reduction and shielding effectiveness. The best configuration for reduction of jet noise used state-ofthe-art technology chevrons with a pylon above the engine in the crown position. This configuration resulted in jet source noise reduction, favorable azimuthal directivity, and noise source relocation upstream where it is more effectively shielded by the limited airframe surface, and additional fan noise attenuation from acoustic liner on the crown pylon internal surfaces. Vertical and elevon surfaces were also assessed to add shielding area. The elevon deflection above the trailing edge showed some small additional noise reduction whereas vertical surfaces resulted in a slight noise increase. With the effects of the configurations from the database included, the best available noise reduction was $40 \mathrm{~dB}$ cumulative. Projected effects from additional technologies were assessed for an advanced noise reduction configuration including landing gear fairings and advanced pylon and chevron nozzles. Incorporating the three additional technology improvements, an aircraft

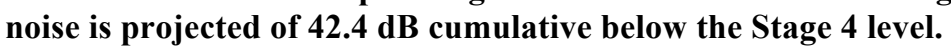

\section{Nomenclature}

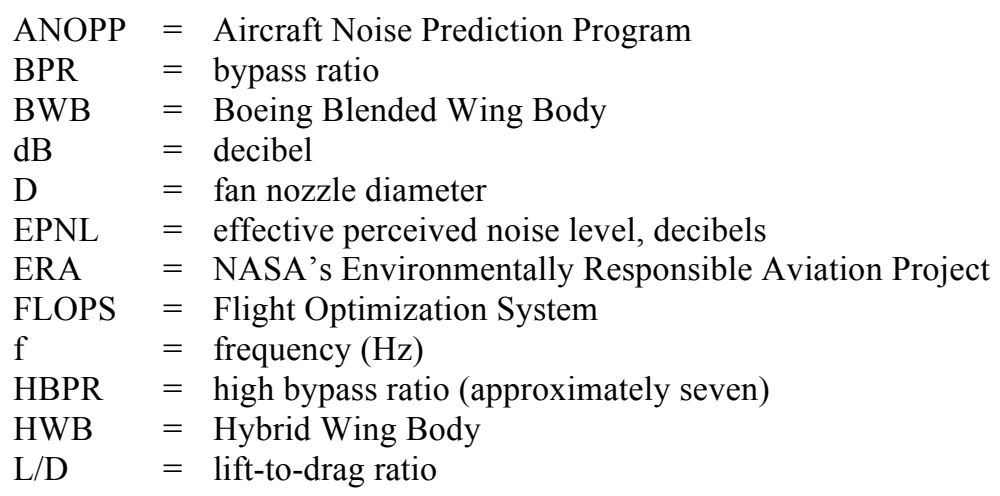

\footnotetext{
${ }^{*}$ Senior Research Engineer, Aeroacoustics Branch, MS 461, Senior Member AIAA, Russell.H.Thomas@NASA.gov

${ }^{\dagger}$ Senior Research Engineer, Aeroacoustics Branch, MS 461, Senior Member AIAA, Casey.L.Burley@NASA.gov

* Senior Research Engineer, Aeronautical Systems Analysis Branch, MS 442, Senior Member AIAA,

Erik.D.Olson@NASA.gov
} 
AIAA 2010-3913

$\begin{array}{ll}\text { LBPR } & =\text { low bypass ratio (approximately four to five) } \\ \text { LSAF } & =\text { The Boeing Company's Low Speed Aeroacoustic Facility } \\ \mathrm{N}+1 & =\text { First generation aircraft beyond current state-of-the-art } \\ \mathrm{N}+2 & =\text { Second generation aircraft beyond current state-of-the-art } \\ \text { NASA } & =\text { National Aeronautics and Space Administration } \\ \text { NPSS } & =\text { Numerical Propulsion System Simulation } \\ \text { PAA } & =\text { Propulsion Airframe Aeroacoustics } \\ \text { PNLT } & =\text { Perceived Noise Level, tone corrected, dB } \\ \text { S } & =\text { noise suppression function } \\ \text { SEL } & =\text { Sound Exposure Level, dB } \\ \text { SOA } & =\text { State-of-the-art } \\ \text { SFC } & =\text { specific fuel consumption } \\ \text { SPL } & =\text { sound pressure level, dB } \\ \theta & =\text { polar directivity angle, degrees, jet axis at } 180 \text { degrees } \\ \psi & =\text { azimuthal directivity angle, degrees }\end{array}$

\section{Introduction}

$\mathrm{N}$ oise generated from commercial aircraft, jet-powered aircraft in particular, has been reduced significantly over the course of the jet age of the last fifty years. The overall reduction actually implemented in the fleet over several decades has been remarkably significant. If early four engine (with very low bypass ratio) jet airliners from the early 1960s are compared to the Federal Aviation Administration's (FAA) current Stage 4 noise certification requirement (Stage 4 in effect since 2006) they would be at approximately $17 \mathrm{~dB}$ cumulative (the addition of the difference between actual noise and the certification limit from the three certification points) above the Stage 4 requirement. In contrast, today's best in fleet twin engine airliners with high bypass ratio engines are approximately $12-15 \mathrm{~dB}$ cumulative below the Stage 4 requirement. This represents, by this metric, a reduction in noise of some 29-32 dB cumulative over five decades. The majority of the reduction occurring in the first two decades, the 1960s and 1970s, was due primarily to the introduction of low bypass ratio turbofan engines with a bypass ratio of approximately four to five. Turbofan engines are an example of aircraft technology with multiple benefits at the aircraft system level. Turbofan engines were primarily introduced for the higher propulsive efficiency resulting in lower fuel burn and longer aircraft range capabilities. However, the higher mass flow at reduced exhaust velocity also reduces the jet mixed velocity directly reducing the jet noise component. Many other innovations have been introduced more specifically for additional noise reduction. The fan rotor to stator spacing was increased to reduce the strength of that contribution to the fan noise component. Improved acoustic liner technology has been developed including the elimination of splices between liner segments ${ }^{1}$. Increasing the total acoustic liner area as well as placing acoustic liner at more critical locations such as closer to the inlet lip has increased the attenuation of engine source noise before it propagates outside the engine nacelle.

A change in aircraft configuration that also had multiple aircraft system benefits occurred with the introduction of the large twin engine aircraft class motivated by reduced weight and drag attributed to the engine installation but also because fewer engines reduces overall part count with favorable cost and maintenance impacts. One of many implications was that engine power requirements for a twin result in aircraft that can climb at a faster rate on takeoff as compared to an equivalent four engine aircraft. The result for the aircraft system noise was that the larger distance to the ground from the faster climb reduced noise directly on the ground.

However, even with all these innovations being aggressively implemented, the progress in noise reduction at the aircraft system level has been slower since 1980 as compared to that in the earlier decades. This leads to the observation that having achieved dramatically lower aircraft noise; there is both increasing technical difficulty and cost of discovering, developing, and implementing new noise reduction technology sufficient to further reduce aircraft noise. This situation is due, in large part, to the fact that aircraft noise of early aircraft was dominated by jet noise whereas modern aircraft have multiple noise sources that are important to address. While production aircraft meet current certification requirements, the combined reality of the continued growth in air traffic, increasingly more stringent environmental goals, and the additional limitations imposed by existing airports, such as curfews, still results in continued strong demand for aircraft noise reduction technology implementation ${ }^{2}$. For these reasons, NASA's Environmentally Responsible Aviation (ERA) project has set a goal of 42 dB cumulative below the Stage 4 certification level with a timeframe of 2020 for key technologies ${ }^{3}$ to be at a readiness level of six (system or sub- 
system prototype demonstrated in a relevant environment). Compared to the noise reduction achieved over the last few decades, this goal and timeframe represent a step change in aircraft noise technology that, if implemented, would dramatically impact positively the flying public and the surrounding communities. In fact, this goal represents about a $27-30 \mathrm{~dB}$ cumulative reduction compared to today's best aircraft that, if implemented, would be an amount approximately equal to the reduction achieved over the last fifty years.

The aircraft configurations that are represented widely in the fleet are typically of two primary types, the engines mounted under the wings and the engines mounted on the aft fuselage with an additional variation (out of production) of these two configurations created by the tri-jet configuration with two engines under the wings and an engine on top of the fuselage at the tail. These configurations were not introduced because of their aeroacoustic characteristics, however each configuration does exhibit specific configuration dependent aeroacoustic effects. Until the last decade, however, relatively little research effort was focused specifically on these aeroacoustic effects related to propulsion airframe integration (distinguished by the term Propulsion Airframe Aeroacoustics (PAA)). From a research point of view, this has largely been the result of limited prediction method capabilities and the more complex experimental approaches required to address integrated propulsion and airframe aircraft systems. Even with these challenges, PAA does represent an area of opportunity to develop noise reduction for conventional configurations and particularly, with a longer horizon, for unconventional aircraft configurations ${ }^{4}$. The opportunity is attributed both to the growing evidence of the number of PAA effects involved in aircraft configuration as well as the magnitude of these effects. PAA can include both reducing the noise sources that arise specifically from integration of propulsion and airframe and using the installation itself as a means to reduce noise.

The Boeing Blended Wing Body (BWB) configurations of Liebeck et $\mathrm{al}^{5}$ are specific designs within the general class of HWB aircraft. The Hybrid Wing Body (HWB) aircraft configuration represents an unconventional aircraft concept that introduces the fundamental change of installing the engines on top of a lifting body airframe with the implication of eliminating the traditional high lift system with multi-element flaps. By themselves, these changes relative to the conventional aircraft configurations represent the potential for a paradigm change in noise reduction. For the objective of understanding the aeroacoustic characteristics of a HWB configuration and quantifying its noise reduction potential, there has been very little high quality experimental information available. Early aircraft system noise assessments of the $\mathrm{HWB}^{6}$ noted limited potential for noise reduction of the baseline HWB configurations of that timeframe, specifically the Boeing BWB configurations of Liebeck et $\mathrm{al}^{5}$ that have the engine exhaust aft of the trailing edge making shielding of the aft radiated engine noise sources impossible. Even with a limited surface to provide some shielding, peak jet sources are typically located as many as 5 to 7 nozzle diameters downstream and this would severely limit noise reduction from airframe shielding. A two-part strategy has been followed to increase the potential noise reduction of the baseline BWB design. The first part of the strategy was to move the engines two engine diameters forward on the body or equivalently to add an extension onto the trailing edge in order to create shielding of the internal engine noise sources and create the opportunity to provide shielding of the jet noise sources ${ }^{7}$. The second part is a key technical challenge to identify PAA technologies that could reduce jet source levels but also enhance the shielding effectiveness by moving jet sources upstream.

Full systems noise studies for the HWB have proven challenging due to the prior state-of-the-art in noise prediction tools. These tools generally relied heavily on empirical databases and have difficulty in analyzing advanced configurations like the HWB. Airframe noise in particular is very challenging to assess since not only is the HWB's airframe very different from conventional aircraft, but the approach angle of attack is much higher, on the order of 13 degrees, and the local flow characteristics around components are different. It is also difficult to compute realistic takeoff and approach flight trajectories without accurate low speed aerodynamic data, typically from wind tunnel studies. Sizing studies, requiring component weight predictions, are also necessary to determine the correct engine size and engine throttle schedule.

The new aspect of this research is a more rigorous and higher confidence system noise assessment of the HWB aircraft concept. A series of updated prediction strategies are used to perform the system noise assessment of a baseline HWB and then variations on the baseline design that improve the aft shielding, particularly of the jet noise. Flight path and aircraft and engine sizing are provided by NASA engine and aircraft system analysis codes that have been updated to address features of the HWB configuration, see Nickol and McCullers ${ }^{8}$. The Aircraft Noise Prediction Program (ANOPP ${ }^{9}$ ) is used to perform the HWB noise assessment based on numerous improvements in the ANOPP system and combined with key experimental data and technology options provided from a large scale PAA experiment reported in a companion paper by Czech, Thomas, and Elkoby ${ }^{10}$. 


\section{Framework}

\section{A. Previous Studies}

In recent years, there are several notable and relevant studies of HWB aircraft concepts, related technology, and system assessment. Funded by the PAA team at NASA Langley Research Center, Spakovszky at Massachusetts Institute of Technology (MIT) started in 2002 to study an aircraft concept designed from first principles to be functionally-silent ${ }^{11}$, that is with a goal of being below the background noise of a typical well-populated environment. The objectives were to investigate the requirements for an aircraft to meet the functionally-silent criteria, to assess the potential of selected low-noise technologies for such an aircraft, and to conceptualize aircraft configurations and propulsion airframe integration. This approach led to a HWB aircraft concept with aerodynamically clean lifting surfaces that would approach at a very low velocity and a steep glide slope of 4.5 degrees, all contributing to reducing the airframe dominated approach noise to the functionally-silent criteria. To reduce engine noise, a distributed propulsion system was proposed with an effective bypass ratio of 20 either through multiple small engines with very high bypass ratios or multiple fans driven by a common core. Integration with the airframe used a hidden trailing edge that included the performance benefit from the boundary layer ingestion and then engine exhaust from a high aspect ratio (50) nozzle. In addition, Spakovszky proposed additional technologies including an engine air-brake that would use the engine in wind mill mode (through variable pitch blades) to absorb potential energy of an aircraft on approach.

A related but more comprehensive conceptual study was carried out from 2003 to 2006 by a partnership of Cambridge University and MIT and funded by the UK government. This project established noise as one of the primary design drivers. The Silent Aircraft Initiative had the goal of the conceptual design of an aircraft that would have noise imperceptible to the human ear on takeoff and landing in a well-populated area. Again, the concept started with a HWB type airframe ${ }^{12}$ with a highly integrated distributed propulsion system including boundary layer ingestion ${ }^{13}$. The engine architecture had a single core driving three fans ${ }^{14-16}$ in each of three propulsion nacelles with added long ducts that included variable area nozzles, thrust vectoring, and extensive acoustic liner treatment ${ }^{17}$ for aft radiated noise. Airframe noise was reduced with drooped leading edge, landing gear fairing ${ }^{18}$ technologies and operational changes such as a low approach velocity of 118 knots, higher glide slope of 3.9 degrees and landing farther down the runway (displaced threshold). The published noise assessment of the final Silent Aircraft concept predicted $75 \mathrm{~dB}$ cumulative below the Stage 4 requirement ${ }^{19}$ with fuel efficiency competitive with next generation aircraft. A technology readiness level of six (system or sub-system prototype demonstrated in a relevant environment) in the year 2025 was assumed.

In sum, both of these studies, the earlier MIT study and then the Silent Aircraft Initiative, clearly showed the large array of advanced technologies and operational changes that would be necessary to target such an extreme noise goal. Nickol $^{20}$ compiled a NASA risk assessment of the Silent Aircraft Initiative's concept listing the many, high risk technologies, air traffic system management, and cost challenges that would be required to achieve a 2025 readiness timeframe.

NASA began a pathfinding study in 2003 with a different goal and strategy but also with the HWB as the basic aircraft configuration. With the growing interest over the last decade in advanced aircraft configurations that could enable a step change in noise reduction, there have been several very successful international workshops including the $8^{\text {th }}$ CEAS Aeroacoustics of New Aircraft and Engine Configurations held in Budapest, Hungary, November, 2004 and the Revolutionary Aircraft for Quiet Communities Workshop held in Hampton, Virginia, USA in July, 2007. These workshops showed a breadth of innovative low noise aircraft concepts, conceptual design, and prediction methods. However, these workshops also point out the many gaps in methods and data that are required to perform high quality assessments of an advanced aircraft concept. For these reasons the NASA pathfinding study focused on the HWB concept both for the obvious noise reduction potential but also because there was already a large and growing experimental and computational database related primarily to the aerodynamics and flight controls of the Boeing BWB accomplished through a long term partnership of Boeing and NASA ${ }^{21,22}$. The Boeing Blended Wing Body ${ }^{23}$ (BWB) shown in Figure 1 was used as a representative example of the HWB. Figure 1 shows the baseline, three-engine version of the Boeing BWB with nozzle exhaust plane aft of the trailing edge, trailing edge elevons for flight control, leading edge slat, and winglets with rudders.

The first objective of this NASA pathfinding study was a basic understanding of the PAA effects due to the differences in configuration between a conventional tube-and-wing and the HWB. To accomplish this the two configurations were matched with the same current technology turbofan engines and sized to meet the same mission requirements. The second objective was to understand the implications for noise of the hybrid wing body configuration and assess the potential noise reduction achievable by using fewer and relatively near term 
technologies. The study was primarily performed by Geoffrey Hill of NASA and concluded in 2005 with only some elements of the study published ${ }^{4,7}$ and the final results compiled in presentation form by Thomas $^{6}$ in 2007 . In contrast to flight dynamics or aerodynamics, this study was limited by the almost complete lack of high quality acoustic data or prediction methods for many of the aircraft components, a situation that is generally the case when attempting a complete noise assessment of an unconventional aircraft. The shielding of engine sources, a key PAA effect representing much of the noise reduction potential of the HWB, could not be done adequately at that time with prediction methods. A detailed shielding experiment ${ }^{24}$ albeit with a simplified point noise source ${ }^{25}$ and no flow effect was used to supply the noise assessment with the effect of shielding. Within the constraints of this study the baseline HWB was assessed at a level of $22 \mathrm{~dB}$ cumulative below Stage 4 with aft radiated noise from the jet and fan exit as the components clearly representing the potential for additional noise reduction. The potential for noise reduction was assessed by moving the engines two fan nozzle diameters upstream of the trailing edge to provide some shielding surface for aft radiated noise. Next, a significant assumption was made that PAA technology from advanced chevrons and the pylon effect could, in the physical limit, move jet noise sources, across the whole frequency range, all the way to the nozzle exit. Finally, assuming complete success of this strategy, the potential noise reduction of the HWB was assessed at $42 \mathrm{~dB}$ cumulative below stage 4 . This result then became the basis for the aggressive N+2 noise goal of NASA's ERA project mentioned above. This study showed that with a few key, relatively near term PAA technologies, if successfully developed and applied, the HWB could produce a step change in aircraft noise reduction without a large array of more radical and longer term technologies and operational changes.

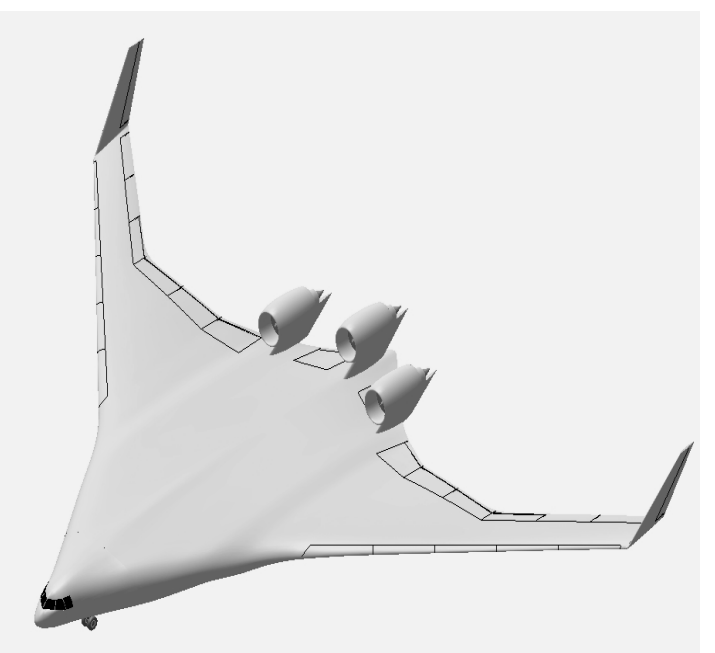

Figure 1. Boeing Blended Wing Body Concept.

\section{B. Current Study Framework}

The framework of the study reported here follows the framework of the NASA pathfinding study. Models of an HWB and a conventional large twin engine tube-and-wing configuration both with the same engine are sized to meet the same mission requirements. The engine represents an existing technology turbofan engine of bypass ratio approximately seven. The tube-and-wing configuration is used as a reference primarily for the system noise calibration given the greater experience base and available aircraft noise data with this configuration. Best available prediction methods for the aircraft and engine models are used (described in Section IV A) and best available system noise methods are used based on the NASA ANOPP (described in Section IV B). The data for shielding effects from the large scale, integrated PAA experiment of Czech, Thomas, and Elkoby ${ }^{10}$ are used in the system noise method. The data used is for configurations that include nozzle, chevron, and pylon technologies as well as elevon deflection and vertical surfaces that can all impact shielding particularly for the aft radiated sources. Furthermore, a limited set of relatively near term technologies are used for additional versions of the HWB and are assessed for additional noise reduction potential.

\section{Propulsion Airframe Aeroacoustics (PAA)}

\section{A. PAA Classification}

In general, the aeroacoustic effects related to propulsion airframe integration, or PAA effects, can be classified in various ways. The following classification begins with a fundamental division of PAA effects into those effects associated with flow interaction and those associated with acoustic propagation, however, it is important to remember that in most cases these are not entirely unrelated issues. With these two fundamental divisions, the classification can be extended to the next level. For flow interaction, the next important division regards the flow direction, upstream or inlet, and downstream or exhaust. Since turbo-machinery and jet noise sources have different characteristics, acoustic propagation effects are more importantly divided along noise sources. The next lowest level of the classification tree is composed of identifying interactions between general engine and airframe components.

5

American Institute of Aeronautics and Astronautics 


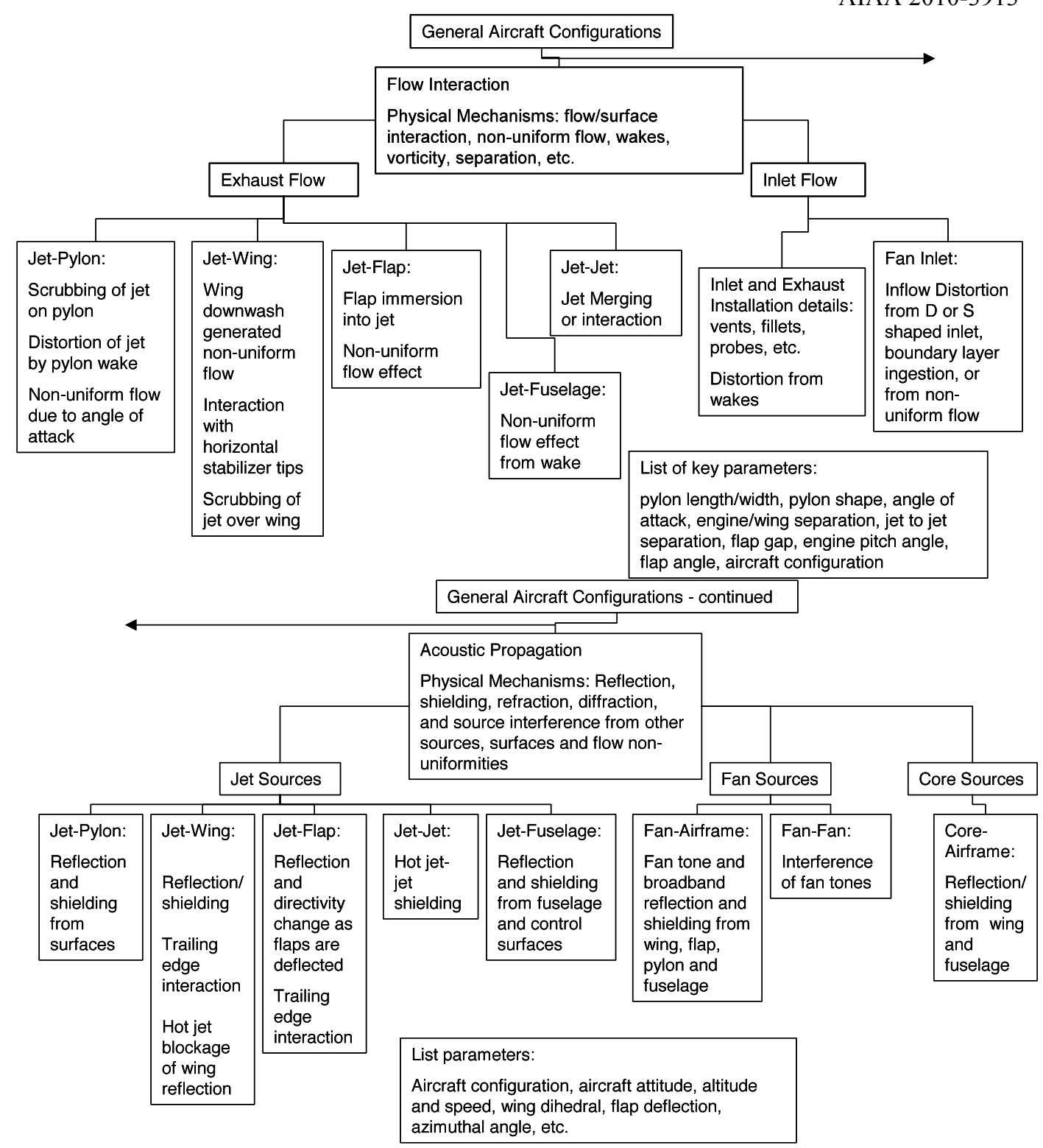

\section{Figure 2. PAA Classification Tree}

And finally, some specific interactions are given along with key parameters. This classification tree is shown in Figure 2 and represents a general way of organizing PAA effects, however at the same time, it is not meant to imply that these effects can necessarily be studied or addressed separately. Rather the opposite is the case particularly on a full aircraft configuration in flight ${ }^{26}$ making the identification and quantification of PAA effects very challenging.

Flow interaction effects are caused by the flow field of one component interacting with another specifically because of the location or orientation of installation. An example of this is the influence of the engine pylon on the jet exhaust flow. The influence of the pylon creates flow features in the jet that are not present in an isolated jet. These features are also influenced by aircraft attitude. Another example is the interaction of the jet exhaust flow with an extended flap and its flow, often observed with the typical engine-under-wing configuration. These types of flow interaction effects from installation can create new acoustic sources or modify existing acoustic sources already associated with the components.

Acoustic propagation effects arise when noise generated from various components propagates and interacts with either structure or flow features created by flow over the airframe and propulsion device. The acoustic propagation of fan noise along the exhaust duct, for example, is altered by the presence of the bifurcator and pylon. Furthermore, the fan noise propagation can be scattered off deployed flaps compared to propagation of fan noise in isolation. Reflection of jet noise from the underside of the wing for the typical engine-under-wing configuration is another example. Acoustic propagation effects are unlikely to create new noise sources specifically due to installation 
effects; however, these effects can conceivably modify existing component noise sources. An example of this modification could be the reflected jet noise interacting with the jet noise sources.

Of course, the type and magnitude of PAA effects of an unconventional aircraft configuration will be dependent on the specific configuration and propulsion airframe technology used. In general, if the goal is a significantly lower community noise impact, it is likely that major effects will have to be included from acoustic propagation such as reflection, scattering, and shielding of propulsion noise sources by the airframe and from flow interaction effects that further enhance the shielding effectiveness by re-distributing sources to more favorable locations.

Out of the general possibilities for significant noise reduction from unconventional aircraft, the most obvious, direct and promising that uses PAA effects is to use the airframe to shield engine noise from ground observers.

\section{B. PAA Technology}

To maximize the HWB's shielding potential, the aft radiating sources, fan exit, core, and jet, must be reduced and shielded more effectively through a combination of changing the baseline configuration of the HWB and through additional technology. This reality has motivated studies to identify methods of shielding the aft radiated sources. A two-part strategy was developed during the course of the NASA pathfinding study to increase the potential noise reduction of the baseline BWB design through both PAA general effects, acoustic propagation and flow interaction effects. The first part of the strategy using acoustic propagation is to move the engines two engine diameters forward of the airframe trailing edge to create some aft shielding of the internal engine noise sources and to create the opportunity to provide shielding of the jet noise sources. Because the jet noise sources are typically distributed many diameters downstream, even two engine diameters of aft shield surface will not accomplish much noise reduction of the key jet noise component. Therefore, the second part of the strategy was to develop flow interaction technologies that may move jet noise sources upstream in order to provide increased shielding effectiveness.

The study that resulted in the large scale integrated PAA experiment reported by Czech, Thomas, and Elkoby ${ }^{10}$ developed the PAA technology and produced the experimental results that, in effect, replace many of the assumptions made during the NASA pathfinding study. PAA technology options were selected based on prior PAA research of interest for conventional configurations, specifically the acoustic effect of the engine pylon ${ }^{27-32}$ and unique chevron nozzles designed to reduce source noise ${ }^{33}$ including favorable interaction with the effect of the pylon $^{33-35}$. The addition of the standard pylon changes the spectra significantly relative to an axisymmetric nozzle (without a pylon), reducing the level at aft polar angles and increasing the noise levels at forward polar angles. This effect is accentuated as the bypass ratio increases from 4 to 7 . The orientation of the pylon was studied primarily at two angles where the pylon either faced the microphones directly or was pointing away from them. The results showed a very significant azimuthal variation with levels as much as $8 \mathrm{~dB}$ higher in the aft arc with the pylon rotated towards the microphones. The source of this basic pylon effect is a flow interaction caused by the aerodynamic closeout of the pylon that alters the development and merging of the primary and secondary flow streams.

Chevron designs generally aim to reduce low frequency jet noise while at the same time minimizing an increase in the high frequency. The design intent for the chevrons in Czech, Thomas, and Elkoby ${ }^{10}$ considered the potential impact of shielding through altering the location of jet noise sources. A more conventional design, Chev1, was developed taking into account the effect of the pylon with a more conservative chevron immersion. Chev2 was a more aggressive design with enhanced immersion to impact the source locations more significantly with the anticipation that the increase in the high frequency part of the spectra could be shielded. All the configurations included in this paper use the Chev2 design. Figure 3 shows the conventional round high bypass ratio nozzle with standard pylon. Figure 3 also shows the Chev2 chevron nozzle.

Prior understanding of the pylon acoustic effect had led to the concept of using the shelf of the pylon as a method of controlling the initial jet development. This could control the merging of the fan and core streams as this mixing process is affected by the presence of the pylon. Furthermore, the control could be made active by injecting a small amount of air through the perforated surface of the shelf. A plenum is contained inside the pylon to provide uniform air through the surface with control of the injection pressure ratio, the ratio of supply pressure to ambient pressure. Computational analysis of the concept set a target range for the injection pressure ratio (1.1 to 1.2) and the porosity of the injection area ( $10 \%$ open area). Hole size ( 0.02 inches diameter) and the 0.1 inch thickness of the injection plate were determined from prior experience. A close up photograph of the active pylon shelf is shown in Figure 4. More detailed discussion of the individual nozzle, chevron, and pylon technology and the experimental results can be found in Czech, Thomas, and Elkoby ${ }^{10}$. The repeatability of LSAF isolated jet noise data is typically $\pm 0.25 \mathrm{~dB}$ for all frequencies and angles. The repeatability of the PAA data is similar and is also discussed for these experiments ${ }^{10}$. 


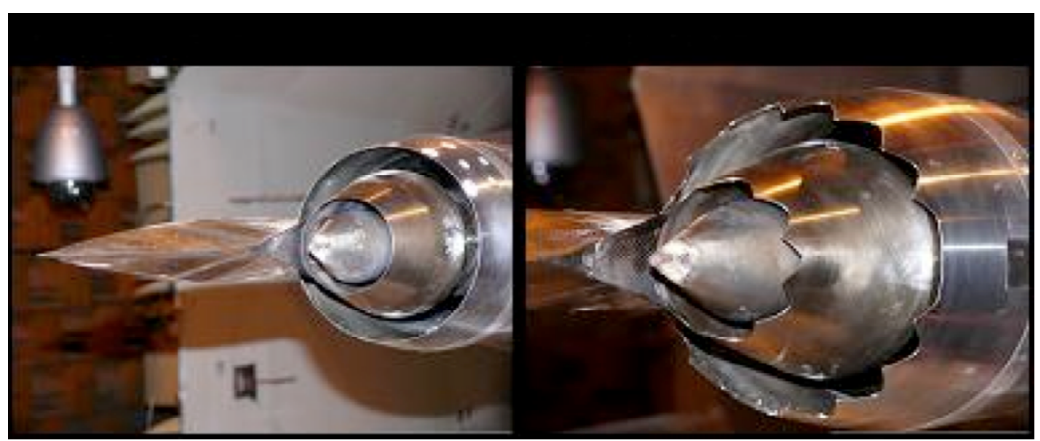

Figure 3: Nozzle configurations, HBPR baseline nozzle with pylon (left) and Chev2 chevron nozzle with pylon (right). Figure from Reference 10.

\section{Hybrid Wing System Noise Assessment}

\section{A. Aircraft and Engine System Models}

Nickol and McCullers ${ }^{8}$ originally described the development of the NASA model of a Boeing 777200ER tube-and-wing aircraft. This NASA model is referred to as a 777like aircraft model and is used as the reference state-of-the-art (SOA) aircraft. A Flight Optimization System $(\text { FLOPS })^{36}$ model was developed using publicly available data for the geometry, weight and performance characteristics of the aircraft and combined with a GE90-like Numerical Propulsion System Simulation (NPSS) ${ }^{37}$ engine model that was developed at the NASA Glenn Research Center. The FLOPS model was then calibrated to match a $656,000 \mathrm{lb}$ takeoff gross weight for a $7500 \mathrm{~nm}$ range mission by adjusting the internallycomputed FLOPS aerodynamic performance and weight predictions to match published data.

Nickol and McCullers ${ }^{8}$ also describe the development of the HWB concept, the HWB300. The HWB300 uses an equivalent mission definition to the 777-200ER reference, including payload, range and reserve mission assumptions. The planform is based on the BWB-450 aircraft, but is scaled down to maintain consistency with the smaller payload in the HWB300. The key low speed aerodynamic performance information included in the FLOPS model is derived from proprietary information of the original BWB 450 aircraft.

The HWB300 aircraft of Nickol and McCullers ${ }^{8}$ was assumed to have a technology level consistent with a 2020 entry-into-service date. Since the purpose of this study was to examine the noise levels of an HWB concept with equivalent technology levels, the advanced engine was replaced with the same GE90-like engines as the SOA aircraft model, and other advanced technologies such as advanced composites, advanced high-pressure hydraulics, variable camber, hybrid laminar flow and embedded boundary-layer ingesting inlets were removed from the model to create an HWB concept with identical mission, payload and technology levels to the SOA reference. The HWB300 engines were scaled to achieve a minimum gross weight while meeting the same takeoff field length as the 777-200ER and meeting all requirements for second-segment and missed-approach climb gradients, resulting in an aircraft with a gross weight of 590,436 lb and sea-level static thrust of 81,298 lb per engine. This HWB300 with GE90-like engines is termed the NASA HWB Best for this study. 
In a preliminary version of this study an earlier version of this HWB300 was used which, among other differences, had an approach speed that was too low for compatibility with the air traffic system but which was within the capabilities of the HWB. This aircraft model is termed the NASA HWB 2009 and is only briefly mentioned in this study.

There still remains uncertainty as to the reduction in gross weight and fuel burn that can be achieved by an HWB configuration. Some of the noise benefit of the HWB is the result of the lighter weight of the aircraft, which requires a lower-thrust and consequently quieter engine. To address the impact on noise of this uncertainty, a heavier version of the HWB300, NASA HWB Heavy, was created with more conservative estimates of the improvements in cruise aerodynamics and structural weight. The heavy version of the HWB300 was derived from the baseline by increasing zero-lift cruise drag to force the cruise $\mathrm{L} / \mathrm{D}$ to a more-modest 21.7 and adding weight to the fuselage to account for the possibility of the center body being ultimately much heavier than what lower-fidelity weights estimation methods predict at this time. The aircraft and engine were sized to the same mission and resulted in a larger engine requirement. The heavy version results in a $6 \%$ lower takeoff gross weight than the SOA.

Due to the high-lift capabilities of the HWB planform, the HWB300 aircraft has a minimum approach speed that is much lower than conventional aircraft of similar size. In the preliminary version of this assessment in 2009 , this resulted in a very low approach speed of 97 knots. There can be a tradeoff between lower speed for reduced airframe noise, the duration effect in the EPNL calculation method, and higher speed for lower engine throttle setting. In this study, a range of approach speeds was examined to determine whether there is an optimum, higher than the minimum, at which noise is minimized. Since approach speed is not an active constraint for this vehicle, increasing the approach speed does not result in a change in the vehicle characteristics.

In addition, the approach speed to be selected in this study must also be compatible with the air traffic system. If the approach speed were too slow this would necessitate increased spacing between aircraft to avoid a faster aircraft overtaking a slower one and violating spacing requirements. Larger and slower aircraft could require a longer separation distance that could negatively impact the air traffic throughput. There are a number of smaller aircraft that do approach at speeds as low as 115 knots, therefore, if the HWB300 minimum approach speed were set at this speed it could still be compatible with the existing air traffic system. Therefore, the approach speed for the HWB in this study was constrained to be 115 knots at a minimum. The effect of aircraft noise as a function of approach speed will be discussed in the results section.

The approach speed capabilities of the HWB also create some alternative possibilities. Sometimes the slower aircraft are separated out and use a smaller runway, which the HWB300 could also use since it has a short landing field length capability. The HWB could also land at different approach speeds depending on the capacity of the air traffic system at a particular airport and time and could use the lower and quieter approach speed at off-peak times such as night or early morning when a quieter approach is particularly valuable.

In sum, the key aircraft system values are shown in Table 1 for the SOA aircraft, the NASA HWB 2009, the NASA HWB Best, and the NASA HWB Heavy aircraft models. All three HWB baseline aircraft versions look similar, Figure 5, in that they are NASA models of a two engine version of the HWB and based on the Boeing BWB aircraft concept.

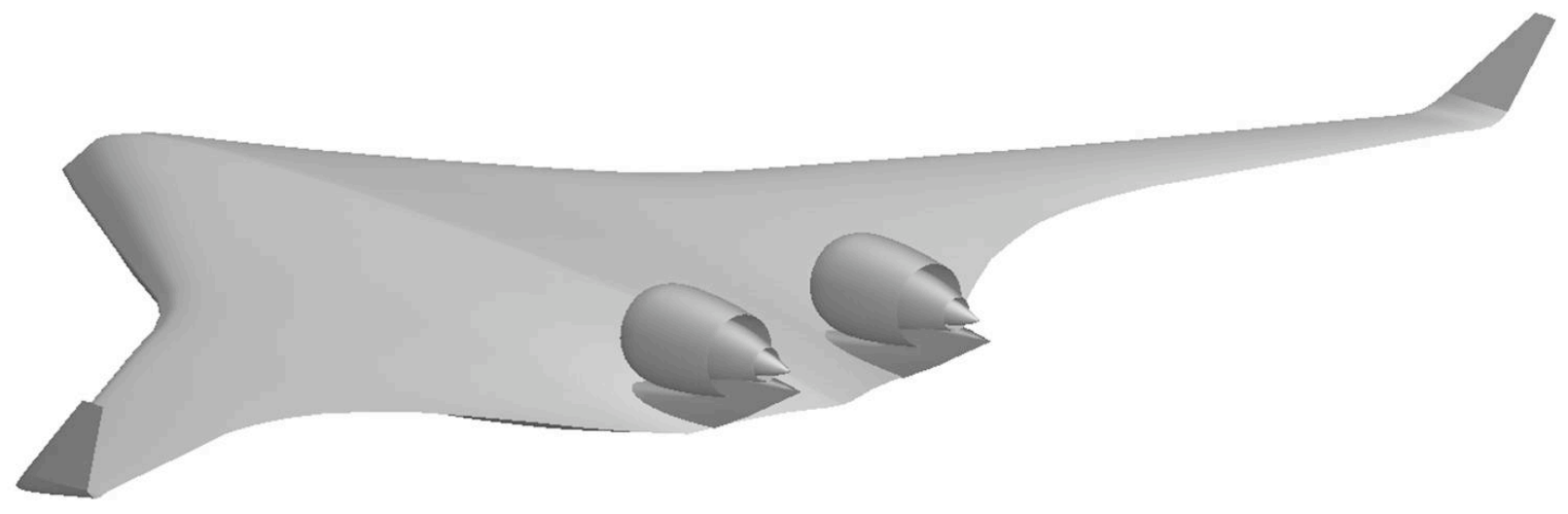

Figure 5. Schematic of a NASA modeled baseline two engine Hybrid Wing Body concept based on the Boeing Blended Wing Body aircraft concept. 


\begin{tabular}{|l|r|r|r|r|}
\hline & \multicolumn{1}{|c|}{$\begin{array}{c}\text { 777-like } \\
\text { SOA }\end{array}$} & $\begin{array}{c}\text { HWB- } \\
\mathbf{2 0 0 9}\end{array}$ & $\begin{array}{c}\text { HWB } \\
\text { NASA Best }\end{array}$ & $\begin{array}{c}\text { HWB NASA } \\
\text { Heavy }\end{array}$ \\
\hline Weight-takeoff (lbs) & \multicolumn{1}{c|}{656,000} & \multicolumn{1}{c|}{572,514} & 590,436 & 617,414 \\
\hline Weight-landing (lbs) & 459,200 & 401,161 & 413,305 & 432,189 \\
\hline Max Fuel (lbs) & 284,279 & 210,665 & 227,081 & 248,666 \\
\hline Engine SFC (lbm/hr/lbf) & 0.557 & 0.550 & 0.549 & 0.548 \\
\hline L/D (start of cruise) & 19.5 & 24.4 & 23.0 & 21.7 \\
\hline $\begin{array}{l}\text { Thrust per Engine (static } \\
\text { sea level) }\end{array}$ & 86,783 & 81,695 & 81,298 & 85,612 \\
\hline $\begin{array}{l}\text { Throttle: Approach (full } \\
\text { throttle = 1.0) }\end{array}$ & 0.190 & 0.201 & 0.129 & 0.132 \\
\hline Throttle: Sideline & 1.0 & 1.0 & 1.0 & 1.0 \\
\hline Throttle: Cutback & 0.78 & 0.75 & 0.76 & 0.76 \\
\hline Takeoff Field-Length (ft) & 8648 & 6270 & 8633 & 8626 \\
\hline
\end{tabular}

Table 1. Summary of the aircraft system values.

\section{B. System Noise Assessment Method}

NASA's Aircraft NOise Prediction Program (ANOPP) ${ }^{9}$ was used to predict aircraft component source noise levels and certification EPNLs for the HWB300 aircraft system with GE-90-like engines. The certification flight procedures as defined by the FAR 36 Stage 3 regulations ${ }^{38}$ were used by FLOPS to predict the flight trajectories for all predictions presented in this paper. The engine state parameters for those flight trajectories were predicted using NPSS for a GE-90-like engine model. Figure 6 illustrates the FAR 36 procedure and the location of the measurement reference points. On approach, the aircraft must fly on a three-degree descent slope at a constant speed with landing gear and flaps down. As described above, the approach speed for the HWB design was constrained to be no lower than 115 knots in order to safely fly within the current fleet. On takeoff, the aircraft must climb at full engine power to an altitude of at least $984 \mathrm{ft}$ (for two engine aircraft), where then a noise abating cutback maneuver may be executed. For both the takeoff and landing procedures, the aircraft must be at its maximum certified weight. The approach and flyover noise measurement points are well defined. The sideline measurement point is where the maximum EPNL occurs along a line parallel to the flight path. To compare the results of the HWB with the SOA, the SOA sideline location is determined and used for the HWB predictions as well.

\begin{tabular}{|c|c|c|}
\hline Noise Source & ANOPP Module & Theoretical Basis \\
\hline Inlet and Fan exit & Boeing Fan Noise & Herkes $^{39}$ \\
\hline Acoustic Liner & GE Liner & Kontos et al $^{40}$ \\
\hline Core Noise & GECOR & Matta $^{41}$ \\
\hline Jet Source & ST2JET & Stone $^{42}$ \\
\hline Landing Gear & BAF & Guo $^{43}$ \\
\hline Flaps & BAF & Guo $^{44}$ \\
\hline Slats & BAF & Sen et al \\
\hline Trailing Edge & FNKAFM & Fink $^{46,47}$ \\
\hline
\end{tabular}

Table 2. ANOPP prediction modules used in this study.

ANOPP is used to predict the engine and airframe noise sources, which are then summed and propagated to the certification measurement locations. Time histories of PNLT are then used to compute the EPNL metric at each location. The engine sources considered are the forward radiated fan inlet noise, aft radiated fan exit noise, core noise, and jet noise. The modules that are used in ANOPP for the current study are listed in Table 2 with references. The airframe sources for the SOA included the main and nose landing gear, leading edge slats and trailing edge flaps. The HWB aircraft does not have flaps and, therefore, HWB airframe noise only included the main and nose landing gear, leading edge slat, and trailing edge noise. The landing gear and flap methods have been well validated and have shown excellent comparison with full-scale 777 data $^{43,44}$. The landing gear description for both the SOA and HWB was taken as that reported by $\mathrm{Guo}^{43}$ for the 777 . It should be noted that the slat method is the least 
developed and least validated, hence it is considered to have a lower confidence level. However, it is included since the slat could be a significant source. The Boeing airframe methods implemented in ANOPP at the time of this paper did not include a trailing edge noise component; hence the older Fink method was used for trailing edge noise prediction. For the HWB, the trailing edge noise is expected to be one of the significant airframe sources and improved prediction methods will be required to accurately predict and truly investigate this noise component.

The airframe can both shield and reflect engine and airframe noise sources depending on the configuration. For the SOA tube-and-wing configuration with the engines mounted under the wing the engine sources will have a direct path to ground observers as well as the potential of reflected noise from the wing surface to the observer. ANOPP provides a capability to estimate this effect based on modeling the wing as a quadrilateral reflective surface. The core, jet and fan exit sources were input into this capability to predict the reflected noise as well as the direct noise to the observers. For the HWB, with the engines mounted above the wing body, the noise will be shielded.

Within ANOPP, the effects of an airframe barrier may be accounted for in two ways, (1) by adjusting the source directivity or (2) by adjusting the propagated noise at the observer. Adjustment of the source directivity is achieved by applying a suppression table to the predicted source noise. This table is generated by calculating a suppression function for each frequency at every polar, $\theta$, and azimuthal, $\psi$, angle on the noise source semi-sphere. The suppression function, $\mathrm{S}$, is the ratio of the shielded to unshielded mean square pressures and is given by

$$
S(f, \theta, \psi)=\frac{P_{r m s}^{2}(f, \theta, \psi)_{\text {shielded }}}{P_{r m s}^{2}(f, \theta, \psi)_{\text {unshielded }}}=10^{\left(\frac{\Delta d B}{10}\right)}
$$

where $\Delta \mathrm{dB}=$ SPLshielded - SPLunshielded . Thus $\mathrm{S}<1$ indicates suppression and $\mathrm{S}>1$ indicates amplification. In this paper the suppression is determined from experimental data ${ }^{10}$ and provided as input to ANOPP. The second approach is to utilize the capability within the WING module of ANOPP. This method is very limited ${ }^{48}$ and the suppression factors determined from the experimental data are considered the only way to account for the complex PAA effects involved in the HWB configurations studied here.

The ANOPP engine noise sources were calibrated utilizing publicly available GE90 EPNL levels in a two-step process. The first step was to obtain the more appropriate relation between the engine noise components. This was done by using data reported by Gliebe ${ }^{49}$ for a GE90 engine on a 777 class aircraft. This engine noise component breakdown, shown in Figure 7, identifies the engine noise components for a prediction and the relative levels between the components. This engine noise breakdown also determines where to focus noise reduction efforts. At sideline, jet is the highest noise source while at cutback both jet and fan exit are equally high and on approach the second highest level is also fan exit. Once the calibration for obtaining the correct relation was determined, the next step was to adjust all the engine component levels by the same amount in order to match the EPNL noise levels for this aircraft (Approach: 98.1, Sideline: 95.0, Cutback: 92.0) .

The engine model, the flight path and vehicle models were all determined from publically available data and are considered representative of a GE90-like engine on a 777-200ER airframe. The predicted engine state parameters and flight path variables are used as input to the noise models and hence directly affect the resultant noise. The calibrations were necessary in order for the GE90-like noise model to closely match the noise levels of a true GE90 engine. Since the same engine is then used on the HWB, it was decided to apply the same total calibration of the SOA aircraft to the HWB to anchor the HWB baseline noise level. This required the assumption that whatever factors resulted in differences between ANOPP predictions and the EPNL levels for the SOA would result in a similar difference when the engine was applied to the HWB. 


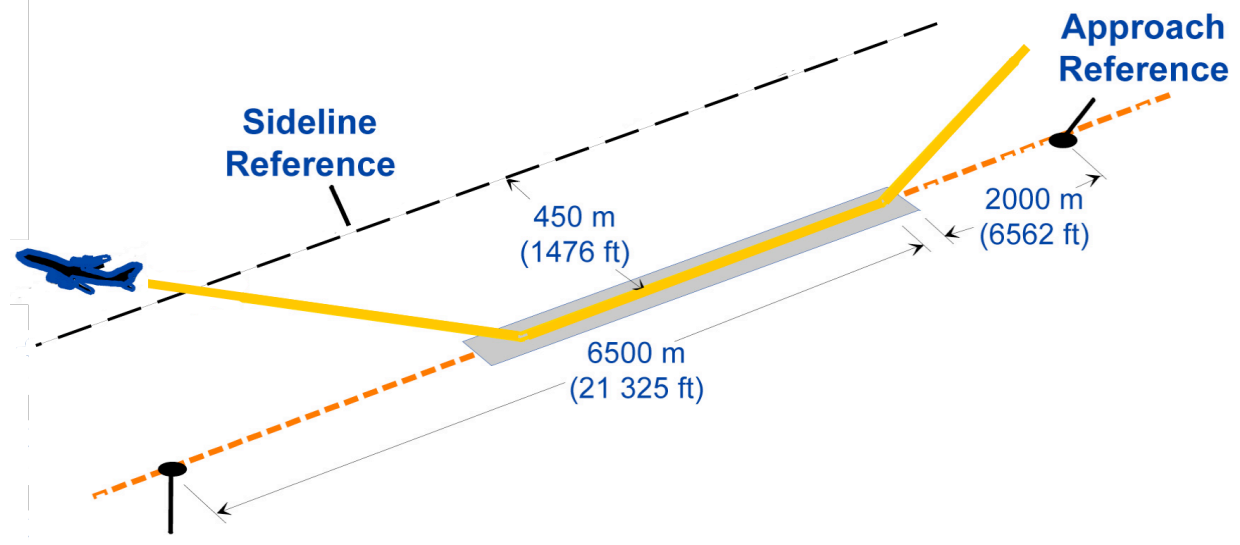

Flyover

Reference

Figure 6. FAR 36 noise certification measurement points.

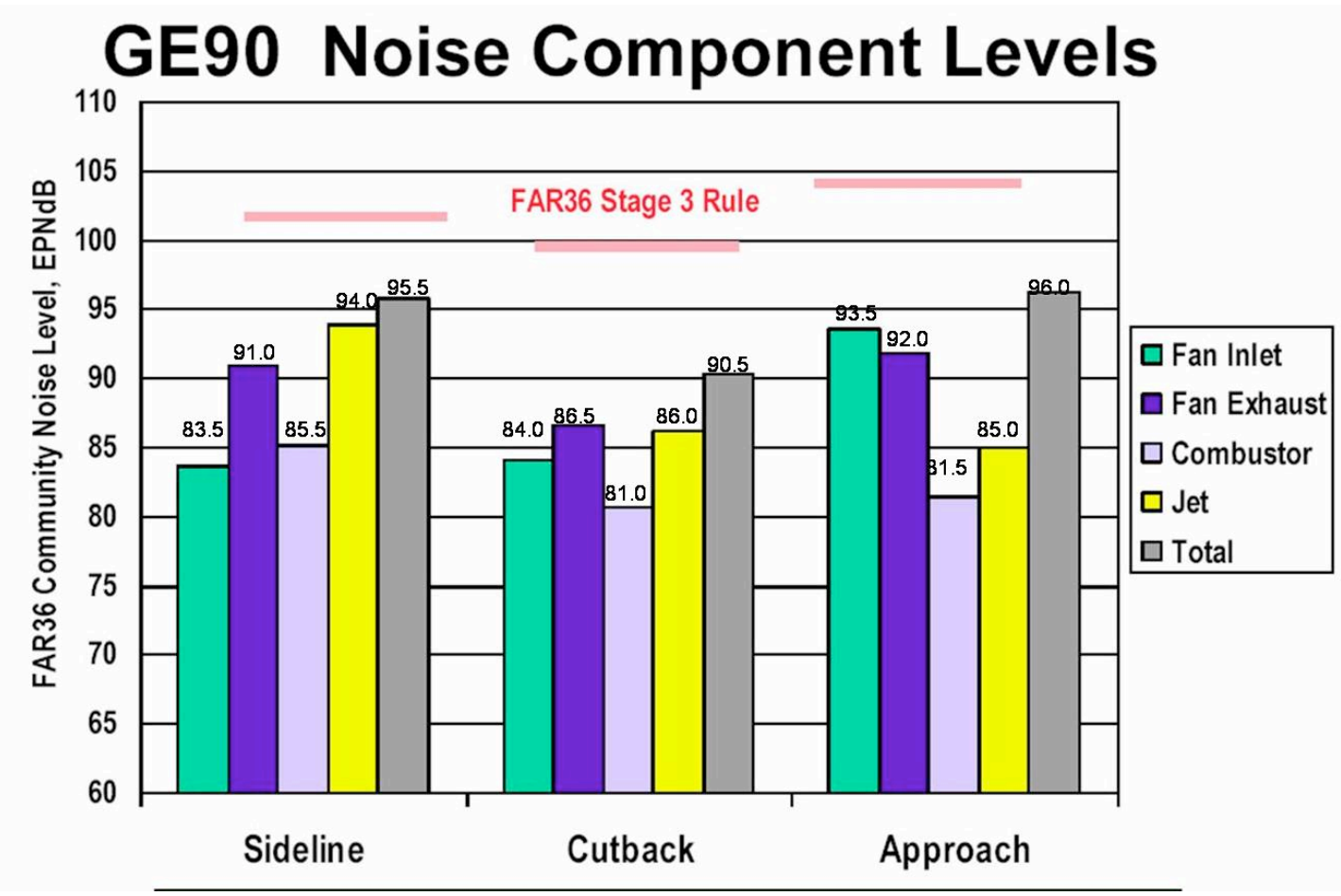

Figure 7. Component noise levels for a GE90 engine from Gliebe ${ }^{47}$. Fan exhaust noise component is equivalent to fan exit.

\section{HWB Aircraft Configurations}

Several configurations are studied in order to accomplish the objectives and provide some insight into the complex effects at the aircraft system level described in the Results section V. Table 3 summarizes the configurations that are described in more detail immediately following.

The original HWB positions the engines with the nozzle exit one fan nozzle diameter downstream of the trailing edge as shown in Figure 1. While the engines must be attached to the airframe by a pylon with the engine centerline about one fan nozzle diameter above the surface, the specific design of the pylon could be of different types. For 
example, the rendering in Figure 1 would indicate a pylon that closes out downstream of the core nozzle exit plane. It is known that this type of pylon configuration can have a significant effect on the jet noise ${ }^{10}$. As described in the ANOPP methodology above, the jet noise with PAA effects is predicted using source prediction from ANOPP with PAA effects added with suppression maps from the LSAF experiments. Taking all these factors together, Configuration 0 of the baseline vehicle is constructed as a reference primarily for the application of the experimental suppression maps to the jet source prediction. Configuration 0 assumes the pylon attaching the engine to the airframe is of a type that has no acoustic effect and that a second pylon in the crown position is of the same type and orientation (relative to an observer on the ground) as on the SOA engine-under-wing configuration. In this way, the jet noise of Configuration 0 matches the ANOPP source prediction as calibrated with the 777-like data. In addition, this also makes Configuration 0, from which the jet noise suppressions will be measured against, the quietest of the possible jet and pylon configurations for the baseline vehicle. In this way, the jet noise suppressions applied for subsequent configurations are more conservative compared to the results of the preliminary assessment performed using the NASA HWB 2009 vehicle $^{50}$.

Configuration 1, shown in Figure 5, makes one fundamental change to Configuration 0 by adding a pylon in the keel position that does extend downstream of the core nozzle exit plane similar to the vehicle rendered in Figure 1. This pylon is of a conventional design that does have a strong flow effect, changing both the jet noise azimuthal noise directivity and source distribution. This pylon is similar to the type of pylon used on conventional under-thewing aircraft. Because this pylon has a strong acoustic effect and is in an orientation that is in the direction of the observers on the ground, the results of Czech, Thomas, and Elkoby ${ }^{10}$ show that the jet noise will actually increase relative to that of Configuration 0 reference.

Configuration 2 makes the next fundamental change by moving the engines two fan diameters upstream of the trailing edge. This provides some limited shielding surface consistent with the noise reduction strategy. Clearly, there are performance impacts of moving the engines upstream on the body closer to the high Mach number region during cruise. These performance impacts are not addressed in this study and are left to future NASA funded work currently underway with Boeing ${ }^{51}$. Rather the emphasis of this study is to determine the acoustic benefit if this change in configuration could be accomplished by some approach that could also minimize the performance impacts. For all of the following configurations in this study, the engine is fixed at this location two fan diameters upstream of the trailing edge.

Configuration 3 adds advanced technology chevrons (Chev2) to the fan and core nozzle of the turbofan nozzle. Configuration 3 also adds the vertical surfaces at the inboard location compared to the wing tip location on the baseline aircraft concept, Figure 8 . The vertical surfaces were considered because proposed low noise versions of the HWB concept have considered moving the vertical control surfaces from the tip to an inboard location ${ }^{51}$ based on the assumption that an additional increment of shielding might be obtained for aft radiating engine sources, particularly at the sideline angle. All other configurations in this paper also include these same vertical surfaces. Configuration 4 is an intermediate configuration and is omitted for brevity.

Configuration 5 adds the active pylon and elevons deflected up by 10 degrees. An HWB has control elevons on the trailing edge of the airframe instead of the traditional high lift flap system. The elevons can deflect up (negative) on takeoff and approach and a 10-degree deflection up is within a reasonable range. Similar to the configuration of the verticals, the elevons represent another option that may provide additional shielding of some of the propulsion sources. The active pylon is set at a high pressure ratio (injection pressure to ambient pressure) of 1.5. However, since the area is small the mass flow at full scale is estimated to be only $0.1 \%$ of the engine mass flow rate and, of course, could be turned off or set at a lower pressure for other reasons at other points in the mission. The tested configuration from Czech, Thomas, and Elkoby ${ }^{10}$ is shown in Figure 8. The active pylon and the elevon effects are only considered on Configuration 5 and not on any of the other configurations.

Configuration 6 rotates the conventional engine pylon from the keel position to the crown position so that this pylon with a known strong acoustic effect is located on the top of the engine. The purpose is to orient the azimuthal directivity in a way that would be favorable, lower noise, in the direction of the observer microphones in the flyover and sideline directions. Of course, an implementation of this configuration would require a second pylon in the keel position of a design that creates a weak acoustic effect but would also meet other vehicle requirements. This could be accomplished in the simplest approach if the pylon could be closed out before the exit plane of the core nozzle, or better before the exit plane of the fan nozzle.

Configurations 1 through 6 represent a subset of the experimental configurations tested by Czech, Thomas, and Elkoby ${ }^{10}$ and are used to supply key data in order to make a full aircraft system noise assessment to be shown in section $\mathrm{V}$ below. The next configurations use additional technologies based on estimates from a variety of sources. The purpose of calculating the system noise assessment of these additional configurations is to understand the impact of additional noise reduction technology or sensitivity of system noise to key aircraft characteristics. 
Configuration 7 takes advantage of the crown pylon of Configuration 6 by adding an acoustic liner to the wall surfaces of the crown pylon, internal to the fan nozzle. The fan exit noise component is the second highest component on both approach and cutback and it could be further attenuated with the application of acoustic liner to the crown pylon. This increases the area of acoustic liner in the bypass duct that can reduce fan exit noise and, furthermore, projections of more advanced liner technology can be factored in based, in part, on prior computational results ${ }^{52,53}$. Therefore, the crown pylon can be a rare dual noise reduction device reducing jet noise as well as fan exit noise simultaneously. Configurations 8 and 9 are intermediate configurations and are omitted for brevity.

Configuration 10 is a heavier weight HWB aircraft and was described earlier in section IV A. It has the same technology package as Configuration 7 and is used to indicate the sensitivity of the system noise to aircraft weight. This is the only configuration assessed on the HWB Heavy model.

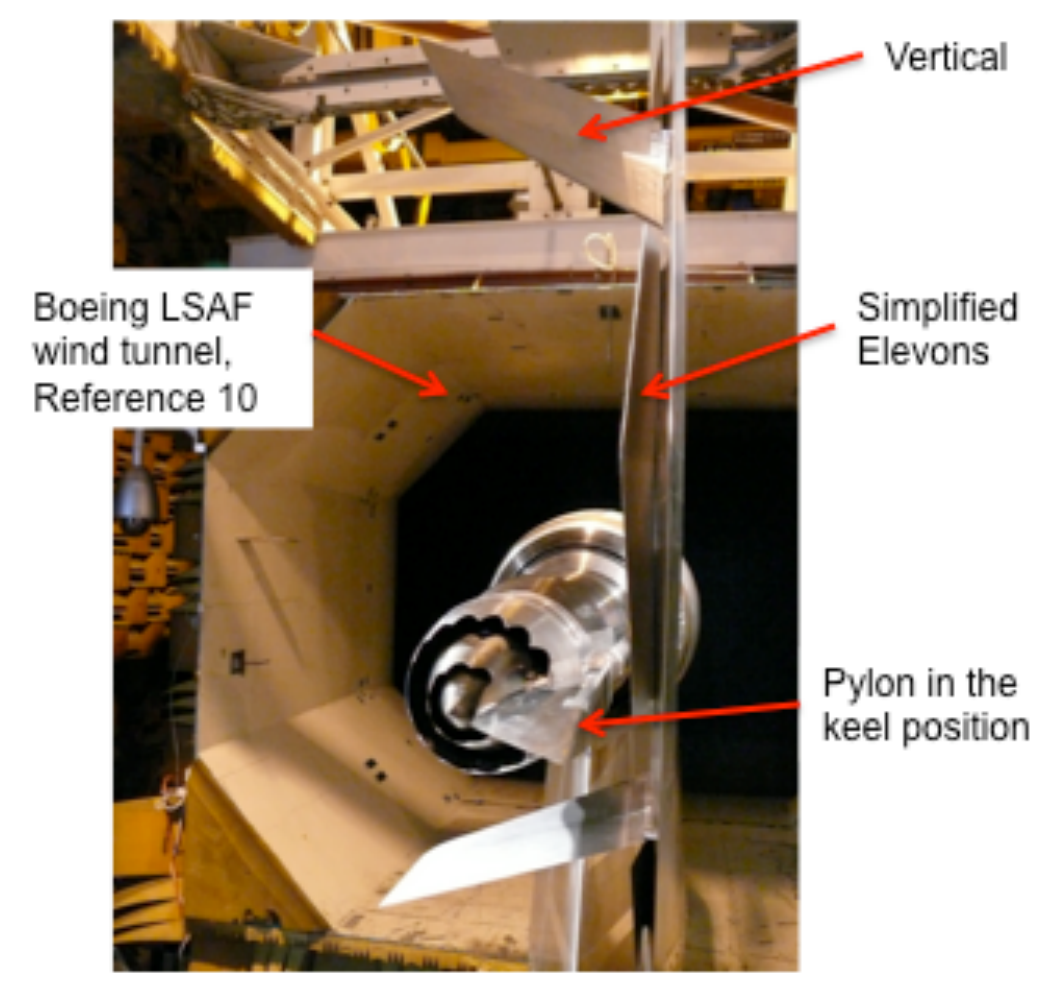

Figure 8. Configuration 5 as tested in Reference 10. Key elements are the Chev2 nozzle with the pylon in the keel position and active pylon injection from the pylon shelf, vertical surfaces, and simplified elevon surfaces deflected up 10 degrees.
Configuration 11 applies additional, but still considered relatively near term technologies to lower the highest components in an effort to quantify a lower noise level that could be achieved within the framework of the current study. Two sources are addressed with additional, projected technology for lower noise landing gear and more jet noise suppression. There is considerable technology development to build on and it is considered that with additional, concentrated development lower noise versions of these components could be available well before the 2020 timeframe. First, even after the source and shielding of jet noise achieved by Configuration 7, the jet related component is still the highest component at the sideline and cutback points. Given the significant noise reduction (source plus

shielding effectiveness) already achieved ${ }^{10}$ and considering that several design variables are effective (chevrons, pylon, and additional technology such as the active pylon), it is reasonable to project that further reduction is possible for the jet component with additional PAA technology development. Second, the landing gear is the highest noise component on approach and because fairings on the landing gear have been extensively researched and even flight tested, it is reasonable that similar technologies could be developed for the landing gear, particularly for a new aircraft concept such as the HWB. The technologies include spoilers, relocation of lights, relocation and fairing of torque links and lines, and fairings on wheels as described and tested at full scale by Dobrzynski et $\mathrm{al}^{54}$. The current study uses the same projection for the noise reduction potential of advanced landing gear fairings as was used in a prior NASA noise assessment for an advanced technology but conventional tube-and-wing aircraft ${ }^{55}$. 


\begin{tabular}{|c|c|c|c|c|c|c|c|c|}
\hline $\begin{array}{l}\text { HWB } \\
\text { Aircraft and } \\
\text { Configuration }\end{array}$ & Purpose & $\begin{array}{l}\text { Engine } \\
\text { Position }\end{array}$ & Vertical & $\begin{array}{l}\text { Elevon } \\
\text { Deflection, } \\
\text { degrees }\end{array}$ & $\begin{array}{l}\text { Nozzle } \\
\text { Type }\end{array}$ & $\begin{array}{l}\text { Pylon } \\
\text { Position } \\
\text { and Type }\end{array}$ & $\begin{array}{l}\text { Crown } \\
\text { Pylon } \\
\text { Liner }\end{array}$ & $\begin{array}{l}\text { Landing } \\
\text { Gear }\end{array}$ \\
\hline Best C0 & $\begin{array}{l}\text { Reference } \\
\text { for jet noise }\end{array}$ & $-1 \mathrm{D}$ & No & 0 & Round & Keel, weak & No & Baseline \\
\hline Best C1 & baseline & $-1 \mathrm{D}$ & No & 0 & Round & $\begin{array}{l}\text { Keel, } \\
\text { strong }\end{array}$ & No & Baseline \\
\hline Best C2 & $\begin{array}{l}\text { Basic } \\
\text { shielding } \\
\text { effect }\end{array}$ & $2 \mathrm{D}$ & No & 0 & Round & $\begin{array}{l}\text { Keel, } \\
\text { strong }\end{array}$ & No & Baseline \\
\hline Best C3 & $\begin{array}{l}\text { Chevrons } \\
\text { for jet } \\
\text { source and } \\
\text { shielding } \\
\text { effect }\end{array}$ & $2 \mathrm{D}$ & Yes & 0 & Chevron & $\begin{array}{l}\text { Keel, } \\
\text { strong }\end{array}$ & No & Baseline \\
\hline Best C5 & $\begin{array}{l}\text { Increase jet } \\
\text { and fan exit } \\
\text { shielding } \\
\text { effectiveness }\end{array}$ & $2 \mathrm{D}$ & Yes & -10 & Chevron & $\begin{array}{l}\text { Keel, } \\
\text { strong with } \\
\text { active } \\
\text { pylon }\end{array}$ & No & Baseline \\
\hline Best C6 & $\begin{array}{l}\text { Crown } \\
\text { pylon jet } \\
\text { directivity } \\
\text { effect }\end{array}$ & $2 \mathrm{D}$ & Yes & 0 & Chevron & $\begin{array}{l}\text { Keel, weak } \\
\text { and Crown, } \\
\text { strong }\end{array}$ & No & Baseline \\
\hline Best C7 & $\begin{array}{l}\text { Fan exit } \\
\text { attenuation } \\
\text { from crown } \\
\text { pylon } \\
\text { acoustic } \\
\text { liner }\end{array}$ & $2 \mathrm{D}$ & Yes & 0 & Chevron & $\begin{array}{l}\text { Keel, weak } \\
\text { and Crown, } \\
\text { strong }\end{array}$ & Yes & Baseline \\
\hline Heavy C10 & $\begin{array}{l}\text { Sensitivity } \\
\text { to aircraft } \\
\text { weight }\end{array}$ & $2 \mathrm{D}$ & Yes & 0 & Chevron & $\begin{array}{l}\text { Keel, weak } \\
\text { and Crown, } \\
\text { strong }\end{array}$ & Yes & Baseline \\
\hline Best C11 & $\begin{array}{l}\text { Projected } \\
\text { reduction } \\
\text { from } \\
\text { advanced } \\
\text { chevrons, } \\
\text { pylon, and } \\
\text { landing gear }\end{array}$ & $2 \mathrm{D}$ & Yes & 0 & $\begin{array}{l}\text { Advanced } \\
\text { chevrons }\end{array}$ & $\begin{array}{l}\text { Keel, weak } \\
\text { and Crown, } \\
\text { strong }\end{array}$ & Yes & Quiet \\
\hline
\end{tabular}

Table 3. Summary of noise reduction HWB configurations for system noise assessment. Engine position in fan nozzle diameters (D) is measured from the core nozzle exit plane relative to the aircraft trailing edge (positive upstream).

\section{Results}

Configuration 6 on the NASA HWB Best aircraft was used to determine the approach noise in EPNL dB as a function of approach speed. The three-degree flight path angle is kept fixed for all approach speeds. The approach speed is varied from the minimum speed for the HWB, 97 knots, used in the 2009 preliminary study ${ }^{50}$ to a speed of 140 knots that is more typical of the 777-like aircraft. Figure 9 shows that the airframe noise decreases continuously with reduced approach speed as expected, while engine noise first decreases as approach speed is reduced from 140 knots, has a minimum near 130 knots, and then increases again toward the minimum approach speed of 97 knots. The result is that total aircraft noise does not minimize until 100 knots, a velocity too low by the criteria already discussed. Therefore, the approach speed is fixed at 115 knots for all cases to be discussed subsequently.

Figure 10 shows the approach velocity as well as takeoff velocity for the four aircraft models discussed. The HWB 2009 model approached at the speed of 97 knots and also had a slower takeoff velocity of about 140 knots. The SOA aircraft has the highest approach speed of 125 knots and the highest takeoff speed approaching 180 knots. The HWB Best and Heavy aircraft have virtually identical speeds, lower compared to the SOA aircraft. Throttle settings are shown in Figure 11 showing similar profiles. Figure 12 plots the flight path as a function of distance for both approach and takeoff maneuvers. Again, all four aircraft follow the three-degree approach angle. Ground roll for the HWB 2009 aircraft was not constrained and is shorter given high lift characteristics of the HWB and the lighter weight. For the current study the ground roll for the HWB Best and the HWB Heavy was constrained to equal that of the SOA and is therefore much longer. Even so, the resulting flight paths for takeoff show the faster 
climb of the HWB compared with the SOA, a factor that will influence noise. The angle of attack profiles in Figure 13 show that the HWB Best and Heavy have angles of attack three to four degrees greater than the SOA on both approach and takeoff while the HWB 2009 had angles that were even greater and less practical as was the approach speed of the HWB 2009.

The overall aircraft system noise is calculated for the seven configurations listed above and is presented in Figure 14 as cumulative noise relative to the Stage 4 level. Configuration 1 with the standard pylon in the keel position is assessed at a level of 22.0 EPNL dB below Stage 4. As described in the previous assessments of the baseline configuration this level results from many effects but primarily from lower airframe noise on approach, shielding of fan inlet noise, and the faster climb on takeoff. Configuration 2 reduces the aircraft noise to $31.6 \mathrm{~dB}$ below Stage 4 due to simple shielding effect from the two diameters of shielding surface that primarily impacts fan exit and core noise but has little impact on jet noise.

Starting with Configuration 3, additional shielding surfaces are included and technologies are introduced that can reduce source levels and impact the source distribution so as to enhance the effectiveness of the same shielding surface length. Configuration 3 adds both the inboard verticals and the advanced chevrons that have a significant effect on jet noise shielding effectiveness by relocating peak noise sources upstream for a wide range of frequencies ${ }^{10}$. The cumulative system noise is $35.1 \mathrm{~dB}$ below Stage 4 with the addition of the verticals and these best available chevrons. The verticals potentially have an effect on jet noise shielding but also on the shielding of fan exit and core engine sources. Examining the intermediate calculation steps can determine the net effect of the verticals. Spectral data for the effect of the verticals on jet noise is shown in Reference 10 for the sideline condition and the effect is small. However, for the certification point calculation, the effect on jet noise is to slightly increase noise. Of greater impact is the effect of the verticals on aft radiated fan and core noise. For those components the verticals increase fan exit and core noise about $1 \mathrm{~dB}$ at each of the three certification points. The effect is most probably due to engine sources reflected from the verticals and constructively summing in the direction of the ground observers, but further data and diagnostic efforts would be useful. The effect is considered real and emphasizes the importance of considered the engine and airframe as a system and not as isolated components. As a result of this finding, for the final recommendation based on this analysis, the inboard verticals should be repositioned to winglets as in the original BWB concepts. However, the verticals were included in the experimental data and their effect is included for the remaining configurations to be shown.

Configuration 5, again shown in Figure 8, adds two more effects simultaneously. First, the elevon deflection above the surface does effectively add more shielding. Second, the active pylon injection from the shelf of the keel pylon also adds additional movement of jet noise sources upstream, increasing jet noise shielding effectiveness. This combination results in an additional $1.5 \mathrm{~dB}$ cumulative noise reduction compared to Configuration 3 for a total of $36.6 \mathrm{~dB}$ below Stage 4 .

Configuration 6 rotates the standard pylon from the keel to the crown position retaining the chevrons and the verticals but without the active pylon or the elevon deflection. As described before, the crown pylon orientation has a more favorable jet noise azimuthal directivity and the result at the system level now totals $39.2 \mathrm{~dB}$ below Stage 4 .

It is important to pause at this point to compare the result of Configuration 6 to the same configuration assessed at $41.1 \mathrm{~dB}$ cumulative below Stage 4 in the preliminary version reported in 2009 by Thomas and Burley ${ }^{50}$. The difference of $1.9 \mathrm{~dB}$ cumulative is indicative of the final impact of the many differences between that study and this more precise and rigorous study. These changes were done intentionally to reflect a more accurate HWB model and included fine tuning the HWB Best aircraft flight path, increasing the approach speed, and the different reference for the application of the experimental jet noise suppression maps. Even though the changes mentioned were on the order of 2-3 dB for each of the airframe and the jet noise components these changes together with the others (throttle setting, angle of attack, etc) all resulted in a $1.9 \mathrm{~dB}$ cumulative change for this configuration. While not a calculation of a confidence level, this can be used to indicate the sensitivity to the impact of multiple input parameter uncertainties.

Configuration 7 identifies the effect of adding acoustic liner to the crown pylon to create a dual noise reduction effect. The acoustic liner is the only change from Configuration 6 and the result at the system level is an additional $0.8 \mathrm{~dB}$ of noise reduction. This is a significant impact at the system level and is the result of the still high level of fan exit noise.

The technology package of Configuration 7 is assessed on the HWB Heavy aircraft model to create Configuration 10. The heavier weight has a higher certification level, a difference of $0.57 \mathrm{~dB}$. While the noise level of Configuration 10 does go up, the certification level goes up more resulting in a reduced level relative to Stage 4 that is $40.4 \mathrm{~dB}$, slightly greater than that for Configuration 7. Clearly, a higher weight HWB will have performance impacts, however, for the weight differences evaluated here, the impact on aircraft noise is minimal. 
Configuration 11 adds three additional technologies to address the noise components that are still highest after the effect of the technologies on Configuration 7. Adding projected benefits from more advanced chevrons, pylon technology and, quiet landing gear, Configuration 11 adds $2.4 \mathrm{~dB}$ more noise reduction for a total of $42.4 \mathrm{~dB}$ below Stage 4.

Figure 15 shows the same levels of cumulative noise reduction and compares them to the noise of the reference SOA configuration and to the noise level for an advanced technology tube-and-wing aircraft. This advanced technology aircraft was assessed at $29 \mathrm{~dB}$ cumulative below Stage 4 by Berton, Envia, and Burley ${ }^{55}$ for an aircraft with ultra high bypass ratio (BPR 16) engines mounted under the wing. Configuration 11, even with the existing technology high bypass ratio (BPR 7) turbofan engine, meets the NASA N+2 noise goal of $42 \mathrm{~dB}$ and exceeds the advanced technology tube-and-wing by more than $13 \mathrm{~dB}$.

Aircraft system noise levels are next presented in diagnostic forms in order to better understand HWB acoustics and the PAA impact of the technologies considered. Figure 16 presents the EPNLdB levels calculated at each of the three certification points. The levels of the SOA aircraft are for comparison and illustrate the fact that for this configuration the levels of the three certifications are within 6 to $7 \mathrm{~dB}$ of each other with approach actually having the highest level. Configuration 1 illustrates the paradigm shift in aircraft noise that the HWB introduces with the sideline level now the highest at about $8-10 \mathrm{~dB}$ higher than at the other two points. Approach noise is dramatically reduced by about $10 \mathrm{~dB}$ due to the absence of flaps as well as the lower speed and shielding of fan inlet noise by the large airframe surface forward of the engine inlet. Cutback noise level is also reduced significantly compared to the SOA configuration due to fan inlet shielding and the faster climb of the HWB. Clearly, reducing the jet and fan exit components that are important at sideline conditions will be critical to achieve system noise reduction. The sideline level actually increases due to the pylon orientation effect explained earlier. Configuration 2 shows that the shielding is more effective on the fan sources and therefore at cutback and approach. With the introduction of the chevrons and the crown pylon orientation in Configurations 3 and 6, respectively, the reduction of the jet source and shielding is more effective as evidenced by the reduction in the sideline noise. Finally, with all the technologies applied on Configuration 11, all three certification noise levels have been reduced, however, the distribution is remarkably similar to Configuration 1 with the sideline level 8 to $9 \mathrm{~dB}$ above the other two noise levels.

For a limited set of configurations, 1, 7, and 11, Figure 17 shows the aircraft system noise at all three certification points calculated for the airframe and the engine noise separately. The quiet landing gear is included in the airframe component for Configuration 11 but the other technology effects are added to the engine component because PAA technologies reduce the engine source noise or increase the shielding of the engine source noise as a result of installation. At the sideline and cutback conditions, the application of the PAA technologies results in engine noise levels that are closer to the airframe only levels while at the approach condition the airframe level actually becomes slightly higher than the engine level.

Perceived noise levels are an intermediate step in the EPNL calculation and are shown in Figure 18 for each of the three certification points for the SOA aircraft and four of the HWB configurations. It should be noted that ground reflections were not included in the data plotted in Figure 18, but were included in the EPNL calculations listed in this paper. The inlet shielding inherent in the HWB shifts the peak levels aft of the observer compared to the SOA. The step down in the SOA PNLT curve at the angle of 90 degrees is a result of the simple reflection model used. The HWB with the additional technologies is able to produce even flatter PNLT distributions.

Figure 19 plots the PNLT distributions for just two configurations, 1 and 7, and also shows the component breakdown. The significant changes created by the applied PAA technologies are evident when comparing Configuration 7 to Configuration 1. At the approach condition, landing gear becomes the high source for Configuration 7 after fan exit noise has been reduced so much. At both sideline and cutback, fan exit noise has been reduced much more than jet noise. While having been reduced, jet noise is still the dominant component at both sideline and cutback after the impact of the Configuration 7 technologies. These results led to the selection of the two additional technologies for Configuration 11 and also indicate where future emphasis should be focused to maximize the noise reduction of the HWB.

By meshing the approach and takeoff flight path information for a simulated single event landing and takeoff, ground contours of sound exposure level (SEL) can be assembled. Figure 20 plots the ground contours for the SOA aircraft, the HWB Best with Configuration 7, and the HWB Best with Configuration 11. The HWB configurations show a dramatic reduction in the area within a given ground contour level. If the area of the SOA aircraft is normalized to 1.0, then for the parameters of this calculation the area for the HWB C7 is 0.36 and the area for the HWB C11 is 0.34 for an overall reduction of $66 \%$ in ground area clearly demonstrating the significant potential benefit to airport communities of an aircraft that could realize these noise levels. 


\section{Conclusions}

The HWB aircraft configuration represents an unconventional aircraft concept that introduces fundamental changes in aircraft configuration. This configuration has the potential for a significant step change reduction in aircraft noise. The best available NASA model of a twin turbofan engine HWB was used to perform a system noise assessment with the best available NASA methods. For the important and difficult to predict aft radiated noise sources, a key element of the system noise assessment was the use of experimental data from a large-scale integrated propulsion airframe aeroacoustic interaction experiment. The baseline HWB aircraft with existing turbofan engines assessed at a level of $22.0 \mathrm{~dB}$ cumulative below the Stage 4 level. A configuration based on near term technologies assessed at $40.0 \mathrm{~dB}$ cumulative below Stage 4. This configuration consisted of engines placed two fan nozzle diameters upstream of the trailing edge for shielding. It included chevron nozzles and a pylon oriented in the crown position to reduce jet source noise and relocate jet noise sources upstream for more effective shielding. Also, on the crown pylon was an acoustic liner for additional fan exit noise attenuation.

The noise assessment of an unconventional aircraft remains challenging and the final outcomes are very dependent on the flight path determined by the models, information used for the PAA effects, and the noise reduction technology impacts. The key impact on noise from the aircraft flight path is through the parameters of the throttle setting profile and the low speed aerodynamic performance and the resulting flight path trajectory affecting the takeoff and cutback points. On approach, the glide slope is fixed at three degrees and the approach speed becomes the parameter with the most impact.

Jet noise is the dominant component at both cutback and takeoff conditions and is a particular challenge because of the distributed sources. The total installation of the jet and combining of the pylon orientation at the crown with the aggressive chevron design was very effective at reducing the jet source level and increasing shielding effectiveness. Chevron technology has advanced rapidly in recent years for jet source noise reduction. The fact that chevrons can be effective at the combined objective of source reduction and relocating sources upstream, making the shielding more effective, opens a new design space for integrated pylon and chevron technology. The benefit of the crown pylon is especially valuable for its simultaneous impact on jet source relocation and fan exit noise attenuation. This benefit of the crown pylon should be studied with higher fidelity experiments and assessment because fan noise radiating from the crown area of the fan duct, away from the airframe, has a higher angle relative to the airframe and is less likely to be shielded. The additional attenuation of fan noise from the crown acoustic liner can mitigate this. This study has also identified the importance of reducing landing gear noise at the source.

An additional configuration with further projected noise reduction from quiet technology landing gear and from more advanced PAA chevron and pylon technology assessed at $42.4 \mathrm{~dB}$ cumulative below Stage 4, meeting the NASA N+2 noise goal. From this configuration, additional reductions could be obtained from a few logical approaches. First, the verticals could be moved from the inboard position to winglets for a small noise benefit and for the better aerodynamics of the original HWB concept. This change alone would likely assess the concept at closer to $43 \mathrm{~dB}$. Since jet and landing gear noise would still be the dominant noise components, the technologies relevant to reducing these sources and enhancing jet shielding should be advanced further. And finally, considering a configuration that would include higher bypass ratio engines (approaching BPR 10) that are currently being introduced, this next configuration should be able to exceed the $42 \mathrm{~dB}$ goal by a considerable margin. A representation of this configuration is shown in Figure 21.

A new configuration like the HWB does introduce a new paradigm for noise reduction. Even with its inherent potential, a low noise HWB must be designed from inception with noise as a goal in order to maximize the noise reduction especially including the propulsion airframe aeroacoustic technology developed simultaneously for source reduction and increased shielding effectiveness. The ability to conduct additional trade studies for low noise, efficient HWB configurations is growing given the prior knowledge base from other disciplines, the high quality experimental data and system noise assessment methodology assembled for this study, and the identified advanced airframe, acoustic liner, and PAA technologies.

\section{Acknowledgements}

The authors would like to acknowledge the following for the many valuable contributions that are required for a project of this complexity and magnitude. Dr. Fay Collier, Project Manager of NASA's Environmentally Responsible Aviation Project, provided the funding for this project and has been an enthusiastic supporter of the project throughout. Dr. Michael Czech, Boeing Commercial Airplane Company, was the Principal Investigator of the 2009 HWB PAA experiment and contributed valuable insight into the experimental configurations and data that were used in this assessment. Mr. Ronen Elkoby, Boeing Research and Technology Company, contributed during 
the HWB PAA experiment. Mr. John Rawls, Lockheed Martin Engineering Services, contributed to the calculation process of the system noise assessment. Mr. Mike Jones and Dr. Doug Nark, NASA Langley Research Center, provided guidance on the attenuation potential of the crown pylon acoustic liner.

\section{References}

${ }^{1}$ Herkes, W.H., Olsen, R.F., and Uellenberg, S., "The Quiet Technology Demonstrator Program: Flight Validation of Airplane Noise-Reduction Concepts," AIAA Paper No. 2006-2720, presented at the $12^{\text {th }}$ AIAA/CEAS Aeroacoustics Conference, Cambridge, Massachusetts, May 8-10, 2006.

${ }^{2}$ Burleson, C., "Aviation and the Environment - Managing the Challenge of Growth," Plenary presentation at the First NASA Fundamental Aeronautics Annual Meeting, New Orleans, LA, October 30, 2007.

${ }^{3}$ Collier, F.S., "Environmentally Responsible Aviation (ERA) Project," presentation at the Third NASA Fundamental Aeronautics Program Annual Meeting, September 29-October 1, 2009, Atlanta, Georgia.

${ }^{4}$ Hill, G.A. and Thomas, R.H., "Challenges and Opportunities for Noise Reduction Through Advanced Aircraft Propulsion Airframe Integration and Configurations," presented at the $8^{\text {th }}$ CEAS Workshop on Aeroacoustics of New Aircraft and Engine Configurations, Budapest, Hungary, Nov. 11-12, 2004.

${ }^{5}$ Liebeck, R.H., "Design of the Blended-Wing-Body Subsonic Transport," AIAA Paper No. 2002-0002.

${ }^{6}$ Thomas, R.H., "Subsonic Fixed Wing Project N+2 Noise Goal Summary," presentation at the NASA Acoustics Technical Working Group, December 4-5, 2007, Cleveland, OH.

${ }^{7}$ Hill, G.A., Brown, S.A., Geiselhart, K.A., and Burg, C.M., "Integration of Propulsion Airframe Aeroacoustic Technologies and Design Concepts for a Quiet Blended Wing Body Transport," AIAA Paper 2004-6306.

${ }^{8}$ Nickol, C.L., and McCullers, L., "Hybrid Wing Body Configuration System Studies," AIAA Paper No. 2009-931.

${ }^{9}$ Zorumski, William E., "Aircraft Noise Prediction Program Theoretical Manual," NASA TM-83199, 1982.

${ }^{10}$ Czech, M.J., Thomas, R.H., and Elkoby, R., "Propulsion Airframe Aeroacoustic Integration Effects of a Hybrid Wing Body Aircraft Configuration," AIAA Paper No. 2010-3912, presented at the $16^{\text {th }}$ AIAA/CEAS Aeroacoustics Conference, Stockholm, Sweden, June 7-9, 2010.

11 Manneville, A., Pilczer, D., and Spakovszky, Z., "Preliminary Evaluation of Noise Reduction Approaches for a Functionally Silent Aircraft," AIAA Journal, Vol. 43, No. 3, pp. 836-840, 2006.

${ }^{12}$ Diedrich, A., Hileman, J., Tan, D., Wilcox, K., and Spakovszky, Z., "Multidisciplinary Design and Optimization of the Silent Aircraft," AIAA Paper 2006-1323, 2006.

${ }^{13}$ Plas, A.P., Madani, V., Sargeant, M.A., Greitzer, E.M., Hall, C.A., and Hynes, T.P., "Performance of a Boundary Layer Ingesting Propulsion System," AIAA Paper 2007-0450, 2007.

${ }_{14}^{14}$ Hall, C.A., and Crichton, D., "Engine and Installation Configurations for a Silent Aircraft," ISABE 2005-1164, 2005.

${ }^{15}$ Hall, C.A., and Crichton, D., "Engine Design Studies for a Silent Aircraft," GT2006-90559, presented at the ASME Turbo Expo, Barcelona, May, 2006.

${ }^{16}$ de la Rosa Blanca, E., Hall, C., and Crichton, D., "Challenges in the Silent Aircraft Design," AIAA Paper 2007-0454, 2007.

${ }^{17}$ Law, T., and Dowling, A., "Optimization of Traditional and Blown Liners for a Silent Aircraft," AIAA Paper 2006-2525, 2006.

${ }^{18}$ Qualye, A., Dowling, A., Babinsky, H., Graham, W., and Sijtsma, P., "Landing Gear for a Silent Aircraft," AIAA Paper 2007-0231, 2007.

${ }^{19}$ Hileman, J.I., Spakovszky, Z.S., Drela, M., and Sargeant, M.A., "Airframe Design for "Silent Aircraft"," AIAA Paper 2007-0453, 2007.

${ }^{20}$ Nickol, C.L., "Silent Aircraft Initiative Concept Risk Assessment,” NASA TM-2008-215112, February 2008.

${ }^{21}$ Vicroy, D.D., "Blended Wing Body Low-Speed Flight Dynamics: Summary of Ground Test and Sample Results," AIAA Paper No. 2009-933, presented at the $47^{\text {th }}$ AIAA Aerospace Sciences Conference, Orlando, FL, January, 2009.

${ }^{22}$ Carter, M.B., Vicroy, D.D., and Patel, D., "Blended-Wing-Body Transonic Aerodynamics: Summary of Ground Tests and Sample Results," AIAA Paper No. 2009-935, presented at the $47^{\text {th }}$ AIAA Aerospace Sciences Conference, Orlando, FL, January, 2009.

${ }^{23}$ Kawai, R.T., Friedman, D.M., and Serrano, L., "Blended Wing Body (BWB) Inlet Configuration and System Studies," NASA/CR-2006-214534, 2006.

${ }^{24}$ Reimann, C. A., Tinetti, A.F., and Dunn, M.H., "Noise Scattering by the Blended Wing Body Airplane: Measurements and Prediction," AIAA Paper No. 2006-2474, presented at the $12^{\text {th }}$ AIAA/CEAS Aeroacoustics Conference, Cambridge, MA, 2006.

${ }^{25}$ Clark, L.R. and Gerhold, C.H., "Inlet Noise Reduction By Shielding for the Blended Wing Body Airplane," AIAA Paper No. 99-1937, presented at the $5^{\text {th }}$ AIAA/CEAS Aeroacoustics Conference, Seattle, WA, 1999.

${ }^{26}$ Elkoby, R., "Full-Scale Propulsion Airframe Aeroacoustics Investigation," AIAA Paper No. 2005-2807, presented at the $11^{\text {th }}$ AIAA/CEAS Aeroacoustics Conference, Monterey, California, 23-25 May 2005.

${ }^{27}$ Bhat. T.R.S., "Experimental Study of Acoustic Characteristics of Jets from Dual Flow Nozzles.” AIAA Paper 2001-2183, 2001.

${ }^{28}$ Martens, S., "Jet Noise Reduction Technology Development at GE Aircraft Engines." ICAS Paper 842, presented at the International Council of the Aeronautical Sciences, Toronto, Canada, September 2002. 
29 Thomas, R.H., and Kinzie, K.W., "Jet-Pylon Interaction of High Bypass Ratio Separate Flow Nozzle Configurations," AIAA Paper No. 2004-2827, presented at the $10^{\text {th }}$ AIAA/CEAS Aeroacoustics Conference, Manchester, United Kingdom, May 10-12, 2004.

${ }^{30}$ Massey, S.J., Thomas, R.H., Abdol-Hamid, K.S., and Elmiligui, A.A., "Computational and Experimental Flow Field Analyses of Separate Flow Chevron Nozzles and Pylon Interaction," AIAA Paper 2003-3212, 2003.

${ }^{31}$ Hunter. C.A., and Thomas, R.H., "Development of a Jet Noise Prediction Method for Installed Jet Configurations," AIAA Paper 2003-3169, 2003.

32 Hunter, C.A., Thomas, R.H., Abdol-Hamid, K.S., and Pao, S.P., Elmiligui, A.A., and Massey, S.J., "Computational Analysis of the Flow and Acoustic Effects of Jet-Pylon Interaction," AIAA Paper No. 2005-3083, May, 2005.

${ }^{33}$ Nesbitt, E., Mengle, V., Czech, M., Callendar, B., and Thomas, R., "Flight Test Results for Uniquely Tailored Propulsion Airframe Aeroacoustic Chevrons: Community Noise," AIAA Paper 2006-2438, May 2006.

${ }^{34}$ Mengle, V., Elkoby, R., Brusniak, L., and Thomas, R., "Reducing Propulsion Airframe Aeroacoustic Interactions with Uniquely Tailored Chevrons: Part 1. Isolated Nozzles,” AIAA Paper No. 2006-2467, May, 2006.

${ }^{35}$ Massey, S.J., Elmiligui, A.A., Hunter, C.A., Thomas, R.H., Pao, S.P., and Mengle, V.G., "Computational Analysis of a Chevron Nozzle Uniquely Tailored for Propulsion Airframe Aeroacoustics,” AIAA Paper No. 2006-2436, May, 2006.

${ }^{36}$ McCullers, L. A., "FLOPS Weight Module Documentation, Wate.doc," FLOPS Users Manual, NASA, April 2008.

${ }^{37}$ Lytle, J.K., "The Numerical Propulsion System Simulation: An Overview," NASA TM 209915, 2000.

${ }^{38}$ DOT/FAA Noise Standards: Aircraft Type and Airworthiness Certification, FAR Part 36, June 9, 2004.

39 Herkes, W., "Modular Engine Noise Component Prediction System (MCP) Technical Description and Assessment Document," The Boeing Company, NASA Contract NAS1-97040, August 2001.

${ }^{40}$ Kontos, K. B., Kraft, R. E., and Gliebe, P. R., "Improved NASA-ANOPP Noise Prediction Computer Code for Advanced Subsonic Propulsion Systems. Volume 2: Fan Suppression Model Development,” NASA Contractor Report 202309, December 1996.

${ }^{41}$ Emmerling, J. J., Kazin, S. B., and Matta, R. K., "Core Engine Noise Control Program. Volume III, Supplement 1 Prediction Methods," FAA-RD-74-125, III-I, Mar. 1976. (Available from DTIC as AD A030 376).

${ }^{42}$ Stone, James R., Kresja, Eugene A., Clark, Bruce K., "Jet Noise Modeling for Suppressed and Unsuppressed Aircraft in Simulated Flight," NASA/TM-2009-215524, March 2009.

${ }^{43}$ Guo, Y., "An Improved Landing Gear Noise Prediction Scheme,” NASA/CR NAS1-NNL04AA11B Task NNL06AB63T, The Boeing Company, Huntington Beach, CA, November 2006.

${ }^{44}$ Guo, Y., "Empirical Prediction of Aircraft Flap Side Edge Noise," NASA/CR NAS1-00086 Task NNL04-AD34T, The Boeing Company, Huntington Beach, CA, August 2005.

${ }^{45}$ Sen, R., Hardy, B., Yamamoto, K., Guo, Y., Miller, G. “Airframe Noise Sub-component Definition and Model,” Boeing Commercial Airplane Company, NASA/CR-2004-213255, September 2004.

46 Fink, M., “Airframe Noise Prediction Method," FAA-RD 77-29, U.S. Department of Transportation, Federal Aviation Administration, 1977.

${ }^{47}$ Fink, M., "Noise Component Method for Airframe Noise,” AIAA Journal of Aircraft, Vol. 16, No. 10, 1979, pp. 659-665.

${ }^{48}$ Nark, D., Burley, C., Tinetti, A., Rawls Jr., J., "Initial Integration of Noise Prediction Tools for Acoustic Scattering Effects," AIAA paper 2008-2996, 14th AIAA/CEAS Aeroacoustics Conference Vancouver, Canada, 5 - 7 May 2008.

49 Gliebe, Philip R., “The GE90: Quiet by Design" Quieter Aircraft Engines Through Leveraging New Technologies," Presentation for 2003 Berkeley Airport Noise Symposium Doing the Wright Stuff: 100 years of Aviation and the Environment, http://www.its.berkeley.edu/techtransfer/events/air/2003/pdf/gliebe03.pdf, March 11, 2003.

50 Thomas, R.H. and Burley, C.L., "Progress Toward the N+2 Noise Goal: HWB Propulsion Airframe Aeroacousics Boeing/NASA Low Speed Aeroacoustics Facility Experiment and System Noise Assessment," presentation to the NASA Fundamental Aeronautics Program Third Annual Meeting, Atlanta, Georgia, September 29-October 1, 2009.

${ }^{51}$ Kawai, R.T., "Acoustic Prediction Methodology and Test Validation for an Efficient Low Noise Hybrid Wing Body Subsonic Transport," presentation at the NASA Acoustics Technical Working Group Meeting, December 4-5, 2007, Cleveland, $\mathrm{OH}$.

${ }^{52}$ Dougherty, R.P., "A Parabolic Approximation for Flow Effects on Sound Propagation in Nonuniform, Softwall, Ducts," AIAA Paper No. 99-1822, presented at the $5^{\text {th }}$ AIAA/CEAS Aeroacoustics Conference, Seattle, WA, 1999.

${ }^{53}$ Nark, D.M., Farassat, F., Pope, S.D., and Vatsa, V., "Effects of Bifurcations on Aft-Fan Engine Nacelle Noise," AIAA Paper No. 2004-2988, presented at the $10^{\text {th }}$ AIAA/CEAS Aeroacoustics Conference, Manchester, United Kingdom, May 10-12, 2004.

${ }^{54}$ Dobrzynski, W.M., Schoning, B., Chow, L.C., Wood, C., Smith, M., and Seror, C., "Design and Testing of Low Noise Landing Gears," AIAA Paper 2005-3008, 2005.

${ }^{55}$ Berton, J.J., Envia, E., and Burley, C.L., “An Analytical Assessment of NASA's N+1 Subsonic Fixed Wing Project Noise Goal," AIAA Paper No. 2009-3144, presented at the $15^{\text {th }}$ AIAA/CEAS Aeroacoustics Conference, Miami, FL, May, 2009. 


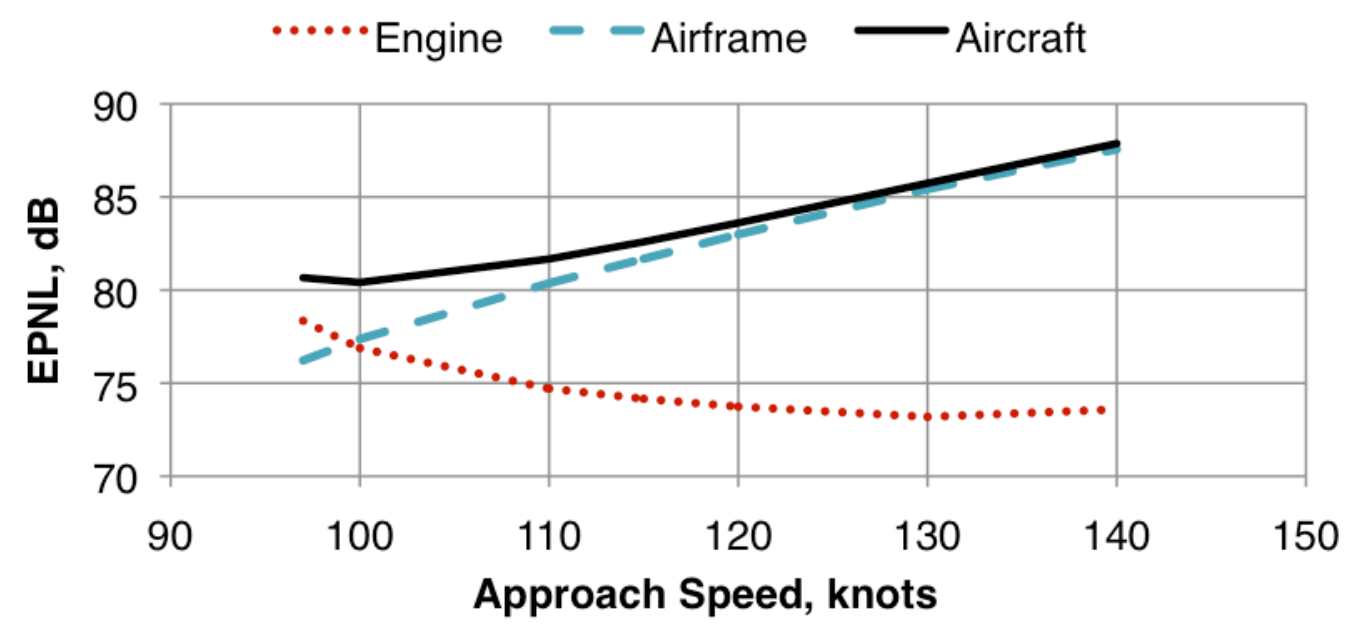

Figure 9. Approach noise for HWB Best with Configuration 6 as a function of approach speed, three-degree flight path fixed.

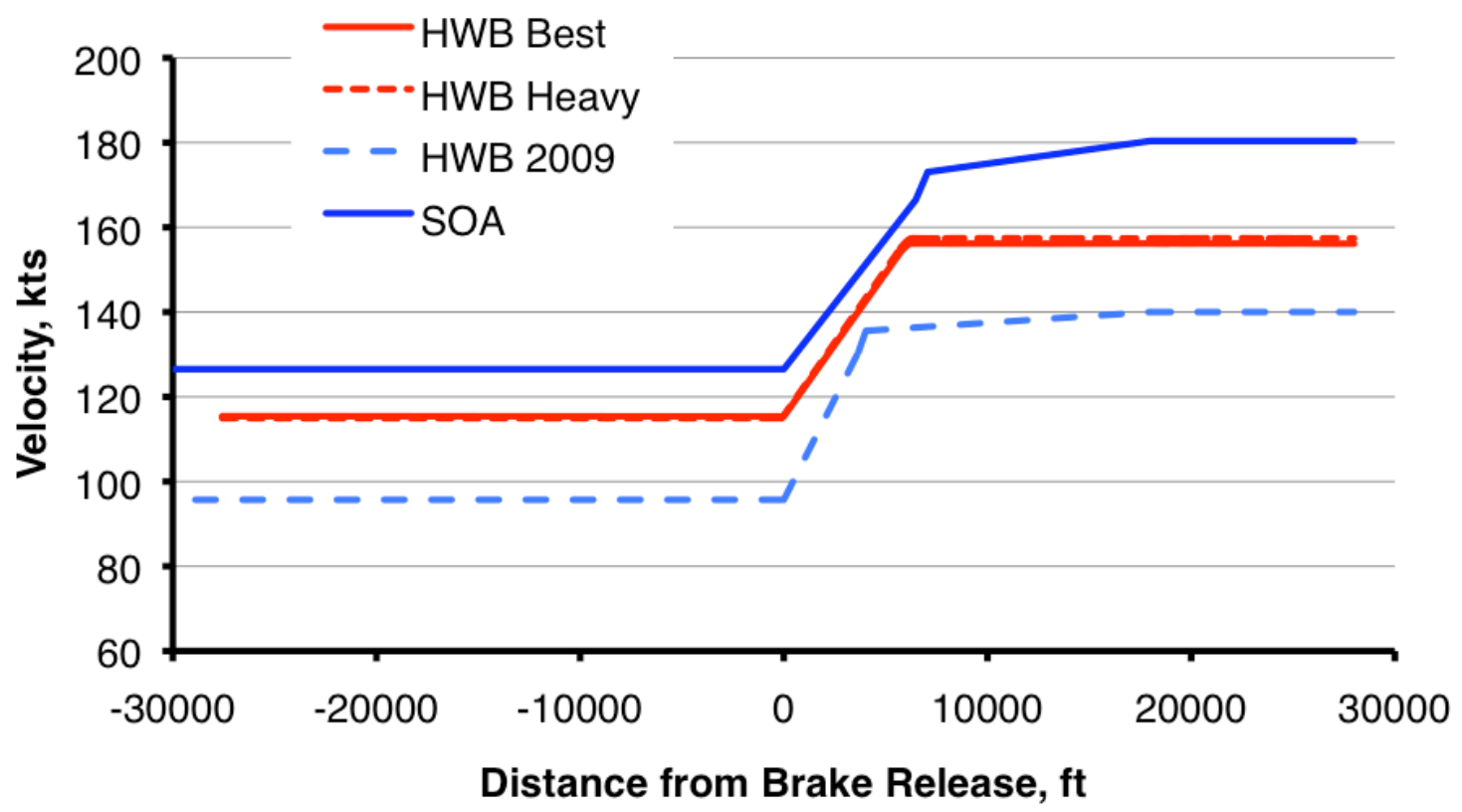

Figure 10. Approach (negative distance toward zero) and takeoff (positive distance away from zero) speed profiles for the SOA, NASA HWB Best, Heavy, and 2009 aircraft models. Note, HWB Heavy and 2009 are virtually identical. 


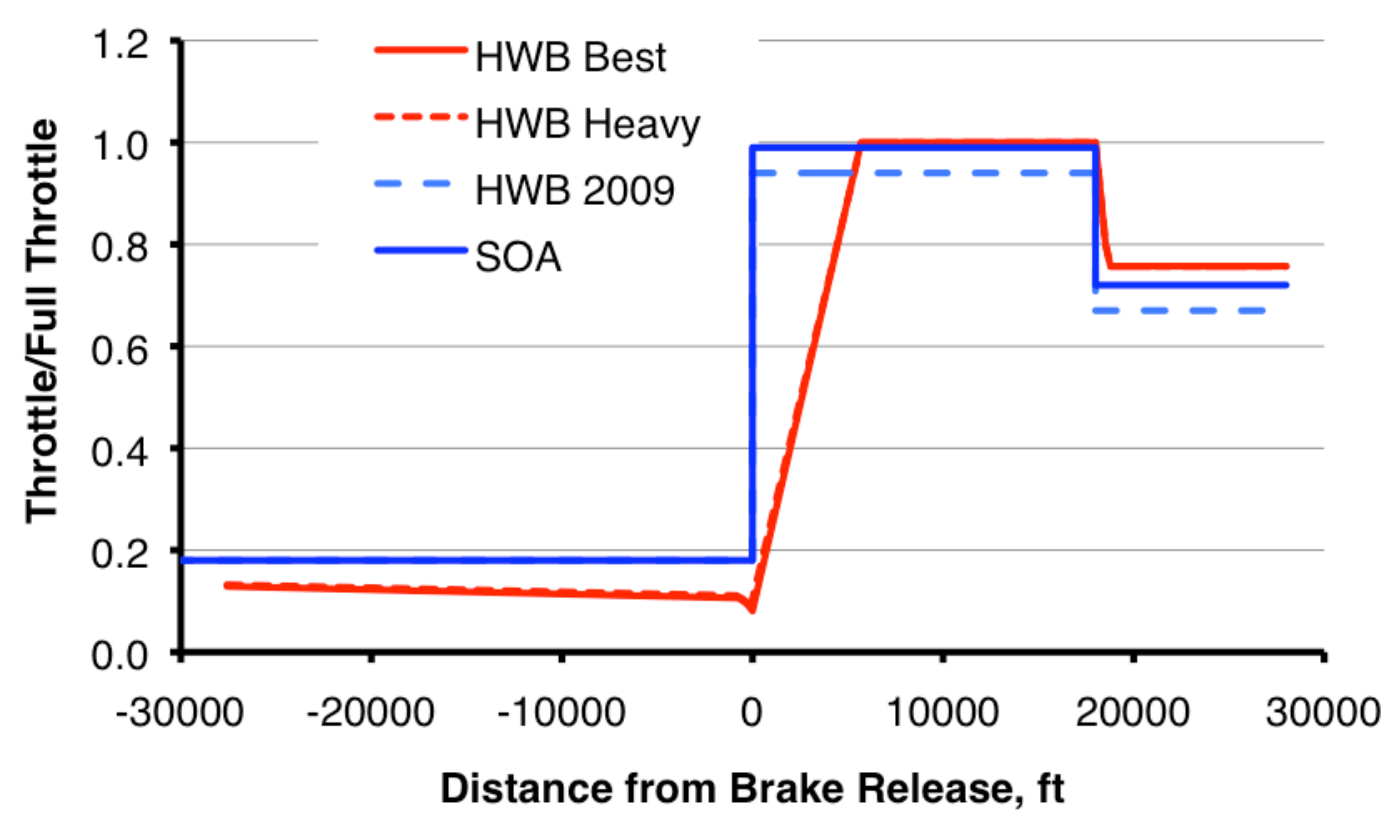

Figure 11. Throttle schedule for approach (negative distance toward zero) and takeoff (positive distance away from zero) as a fraction of full throttle. Note, HWB Best and 2009 are virtually identical

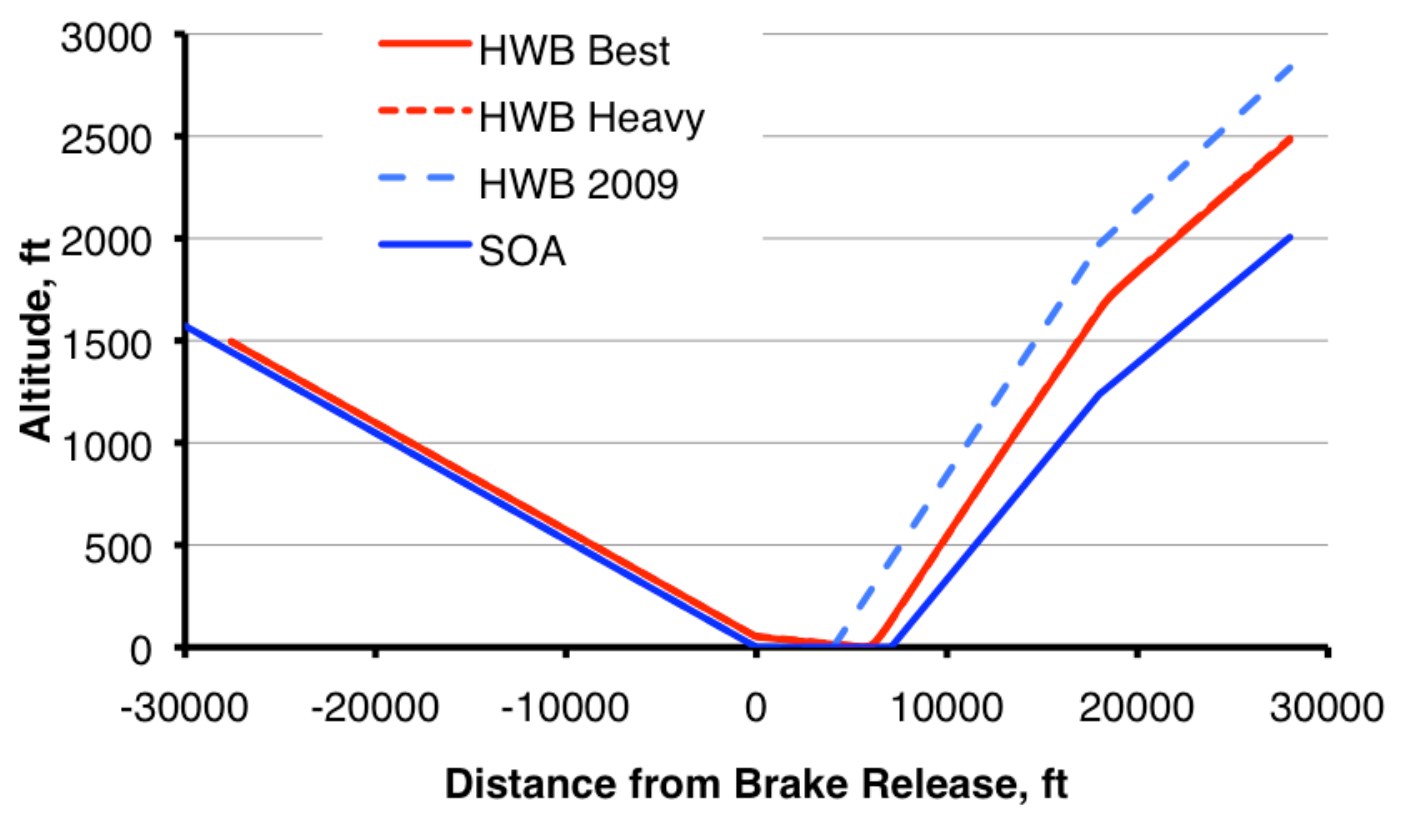

Figure 12. Flight path for approach (negative distance toward zero) and takeoff (positive distance away from zero) manuevers for the SOA, NASA HWB Best, Heavy, and 2009 aircraft models. Also, note the flight path during touchdown and through rotation were not simulated, but estimated. The noise at the certification measurement points are not affected by this part of the flight path. The location of takeoff from the ground however is considered accurate. The HWB-2009 was not contrained to the same takeoff length as the Heavy and Best and therefore had a shorter takeoff length. 


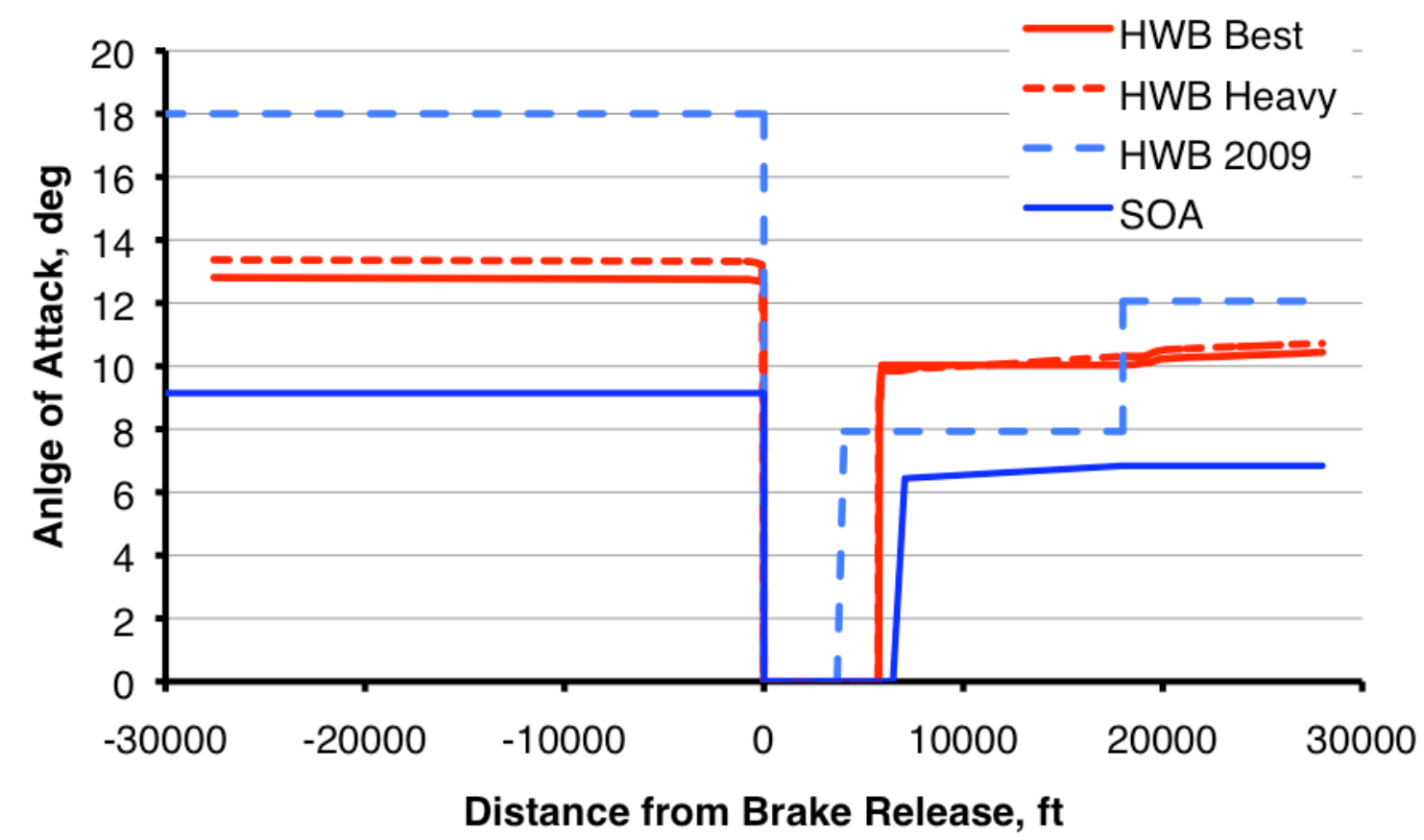

Figure 13. Angle of attack profile for approach (negative distance toward zero) and takeoff (positive distance away from zero) manuevers.

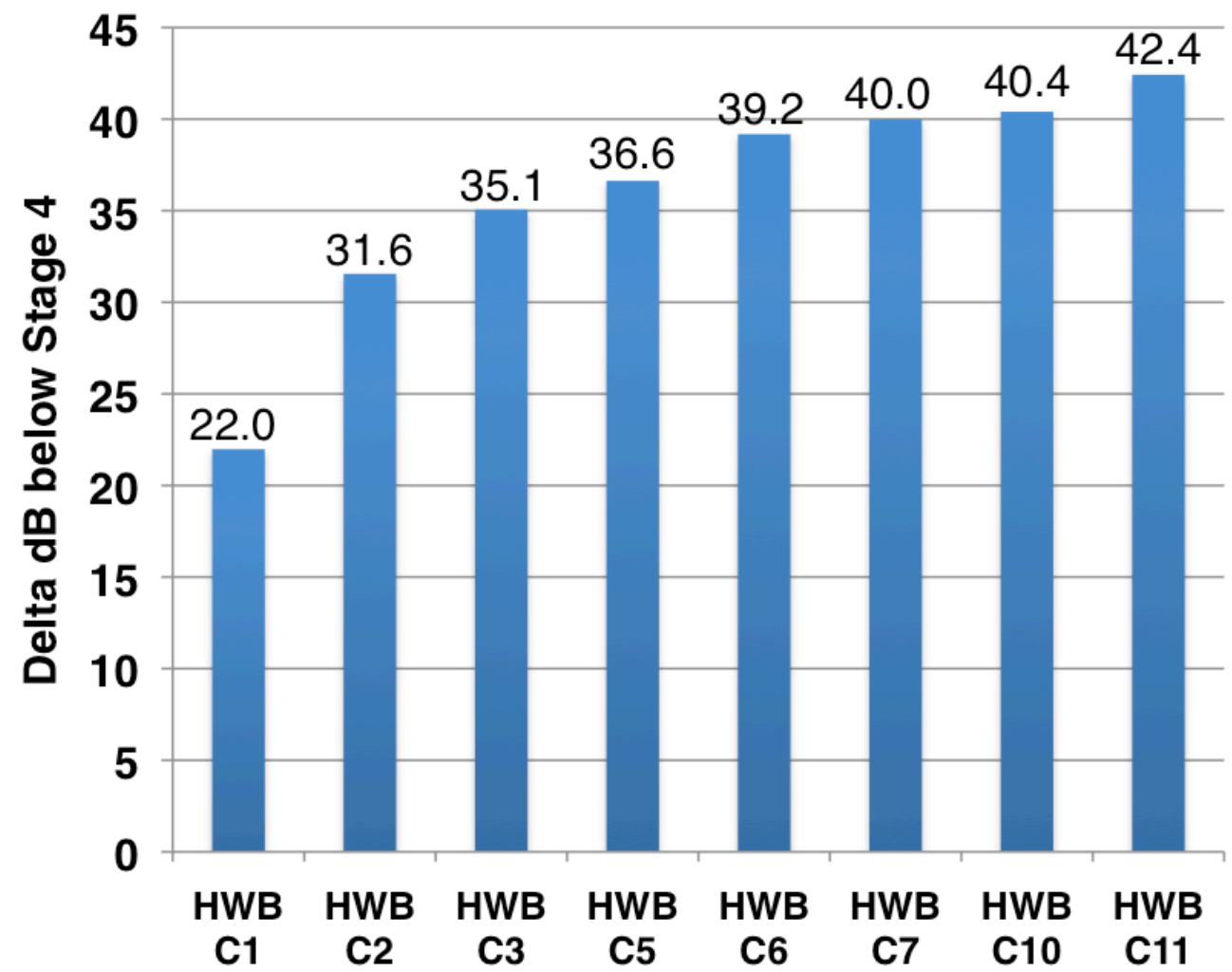

Figure 14. Cumulative aircraft system noise levels relative to the Stage 4 level for HWB aircraft and technology options studied. 


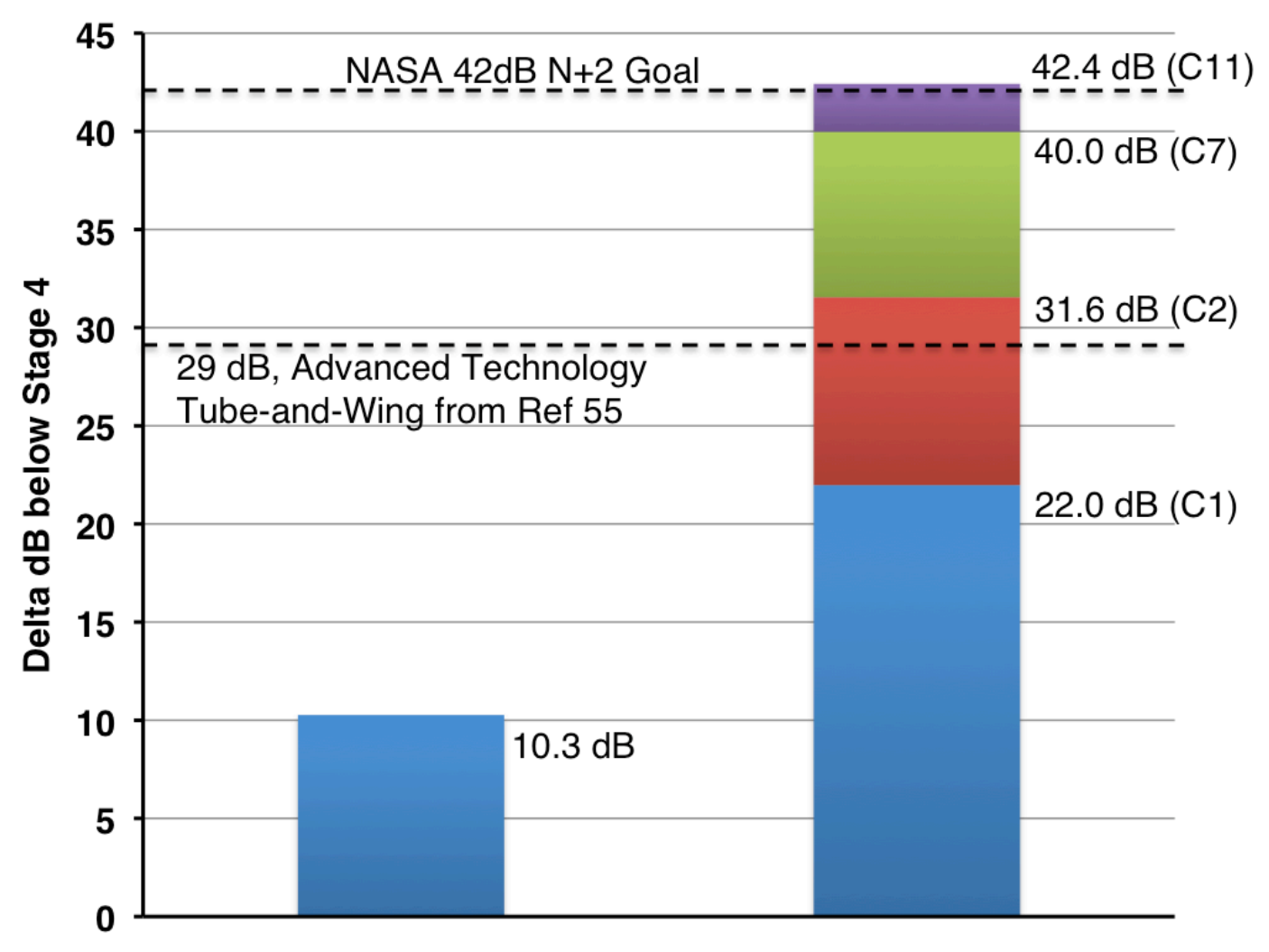

Figure 15. HWB aircraft system noise levels compared to the 777-like SOA aircraft level and the noise level of an advanced technology tube and wing configuration from Reference 55.

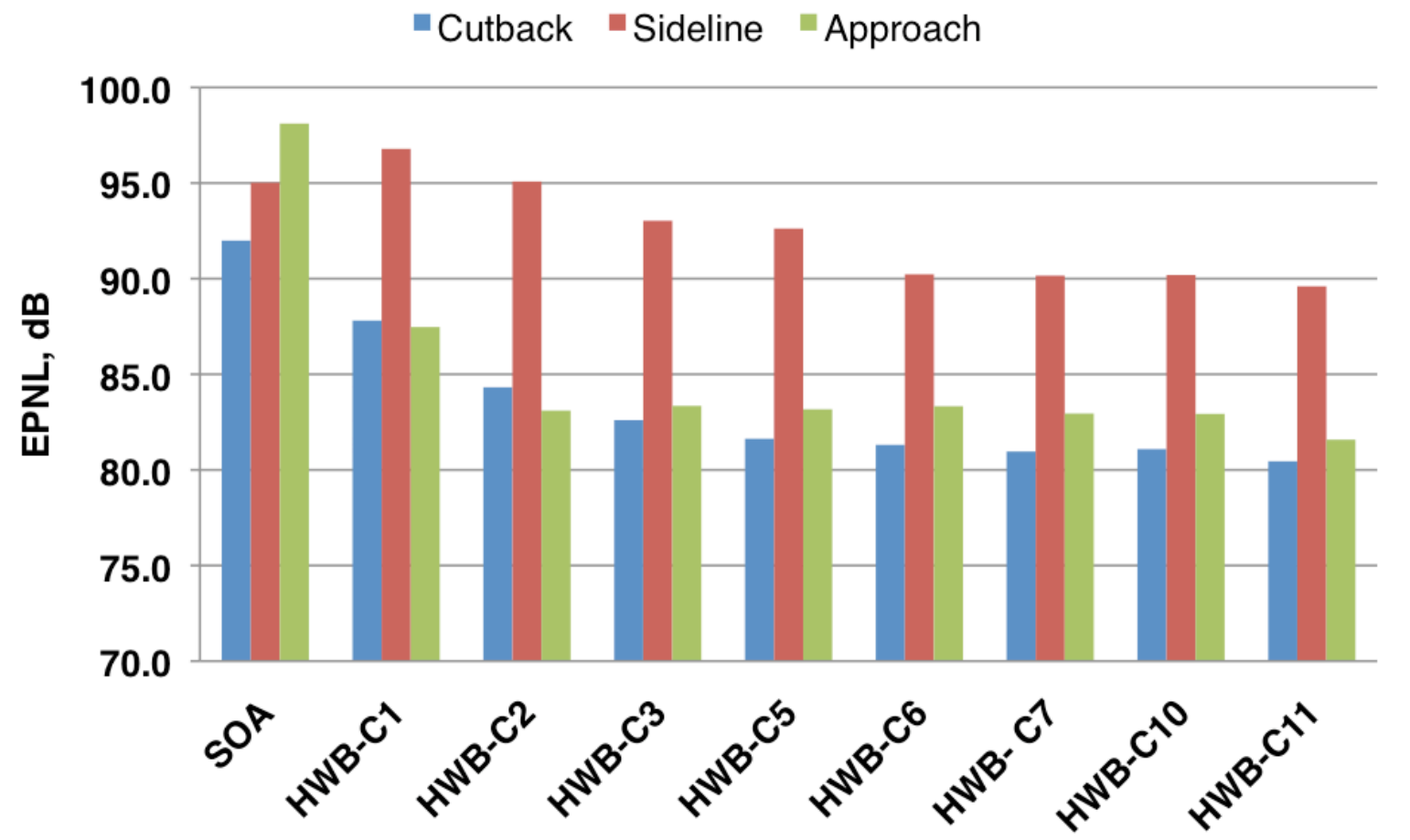

Figure 16. Predicted EPNL for the Boeing 777-like aircraft and different configurations of the HWB . 


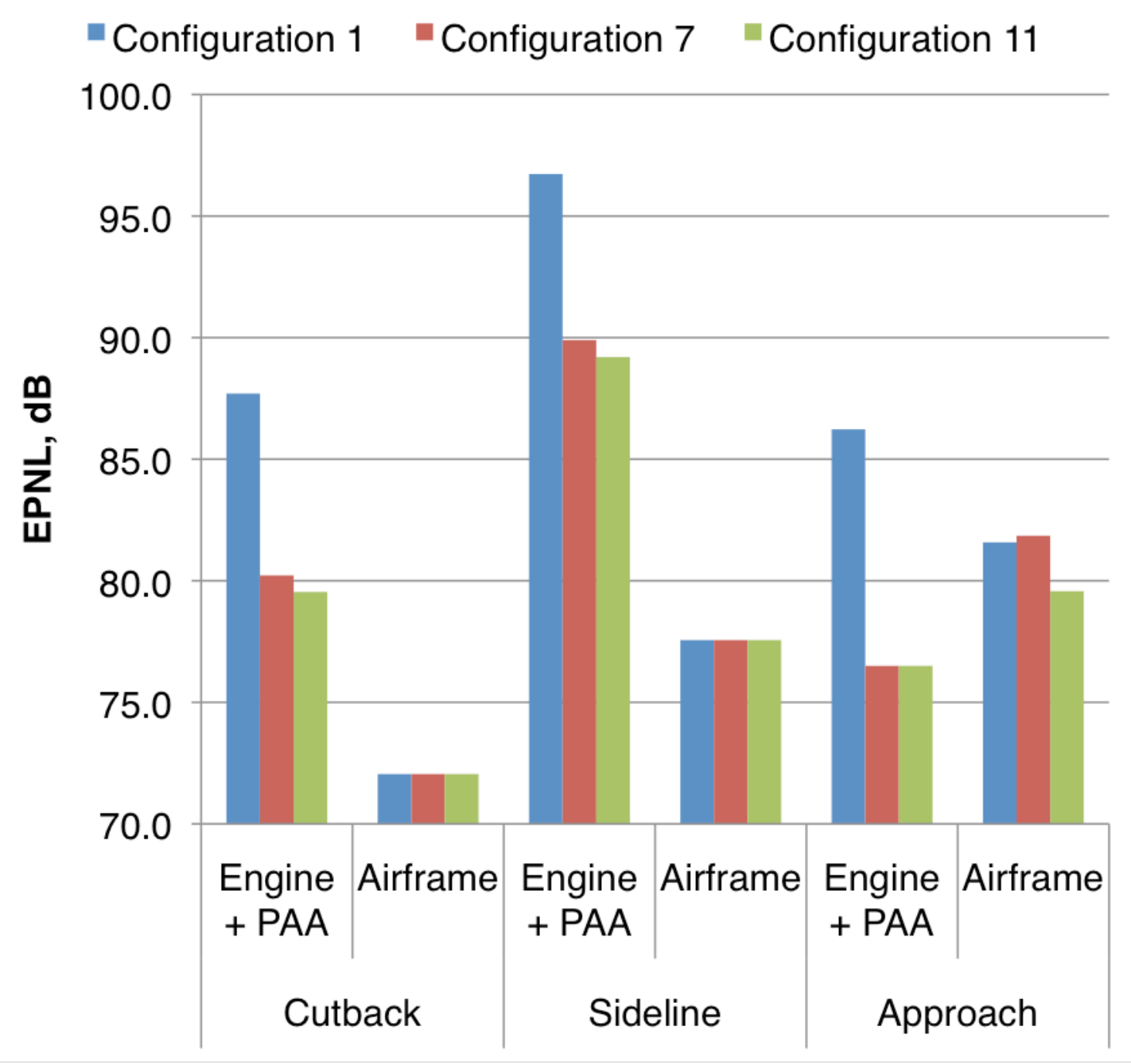

Figure 17. Aircraft system noise levels at the cutback, sideline, and approach points separated by airframe and engine noise with the effects of added PAA technologies. 


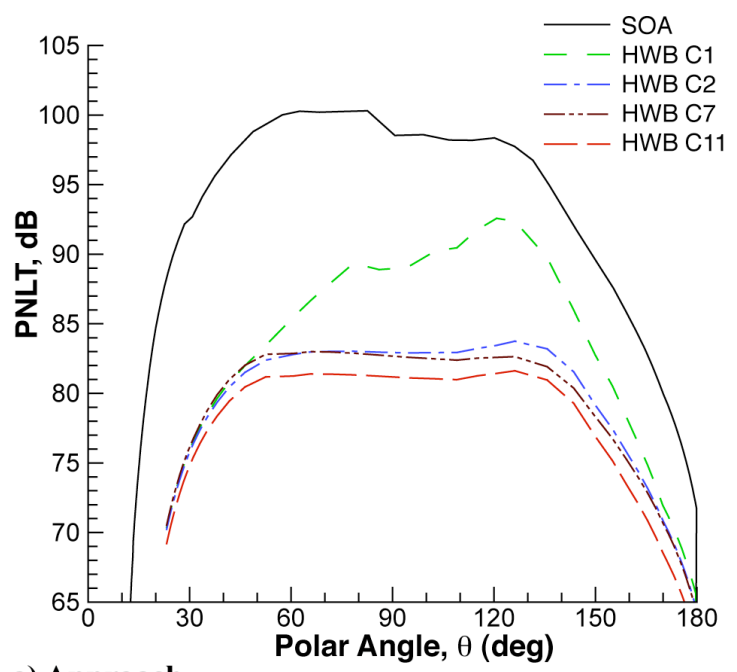

a) Approach

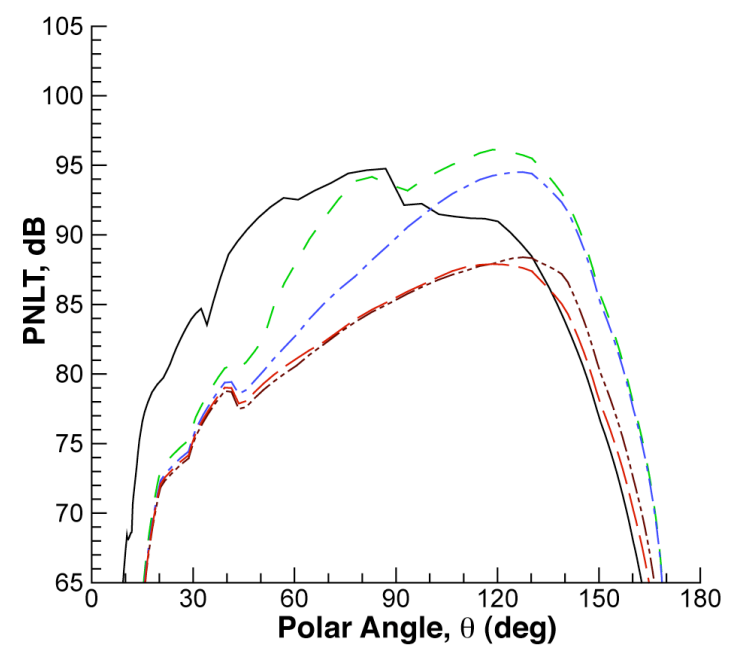

b) Sideline

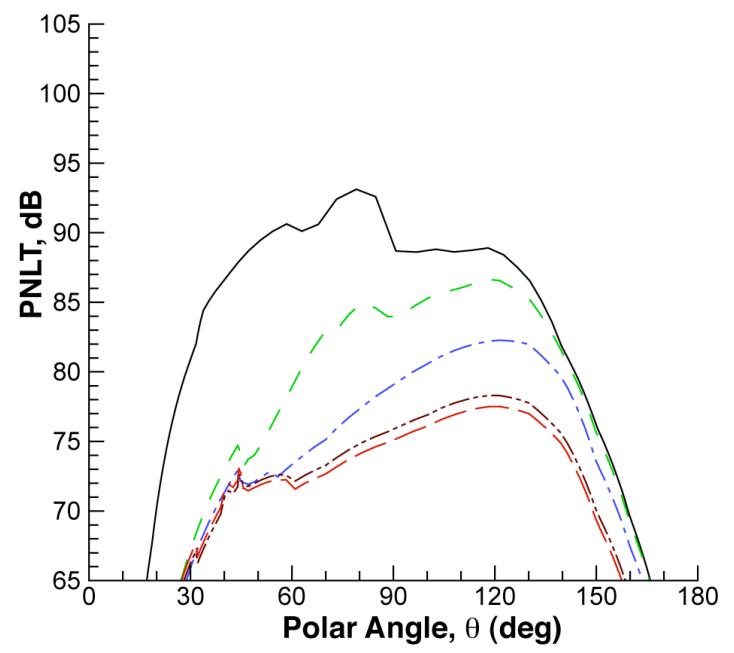

c) Cutback

Figure 18. Tone-corrected perceived noise level, PNLT, as a function of flyover angle (observer at 90 degrees) for a) sideline, b) cutback, and c) approach conditions. 


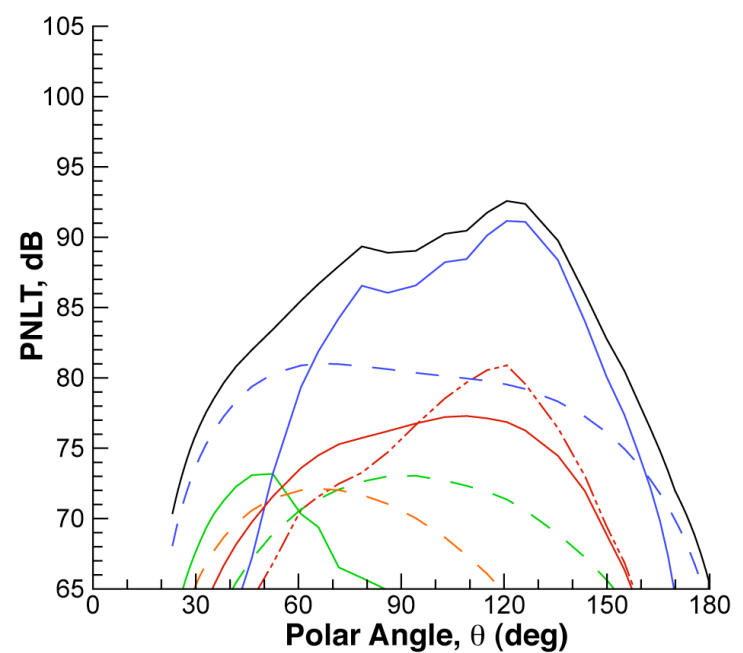

a) HWB C1 Approach

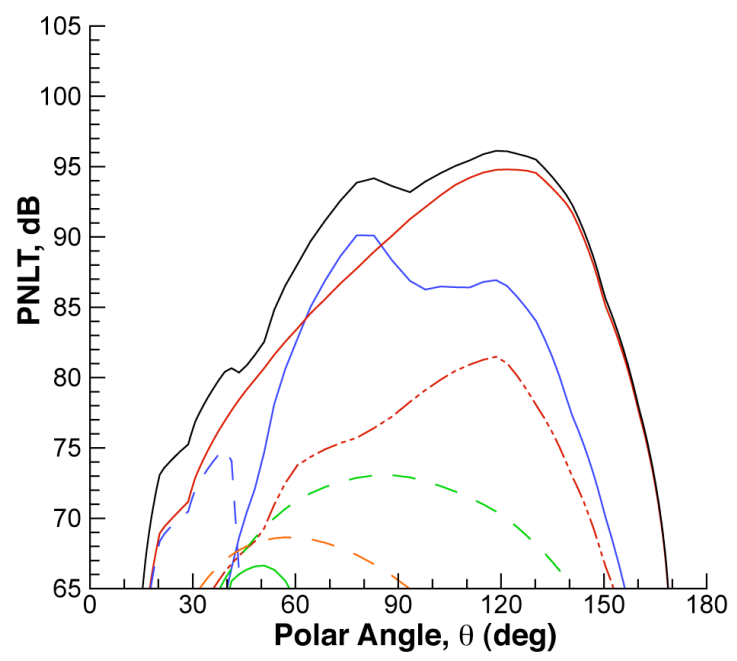

b) HWB C1 Sideline

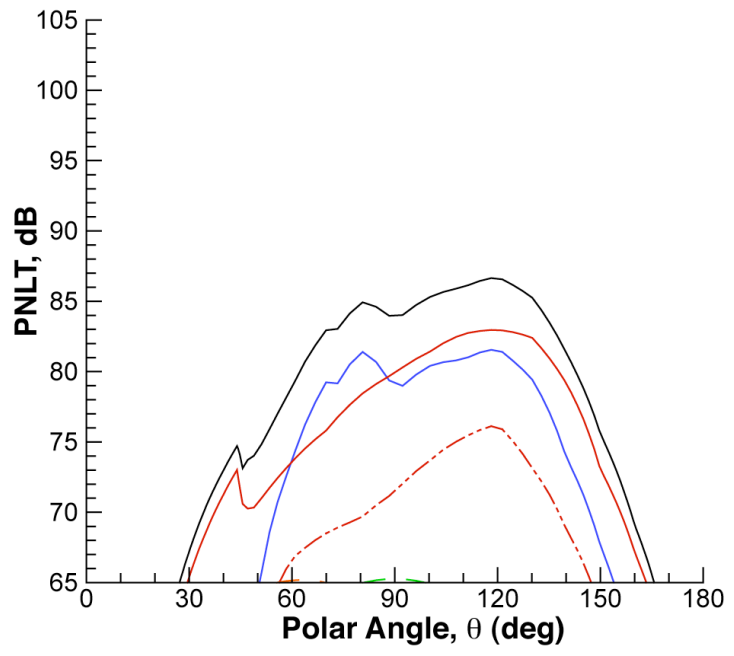

c) HWB C1 Cutback

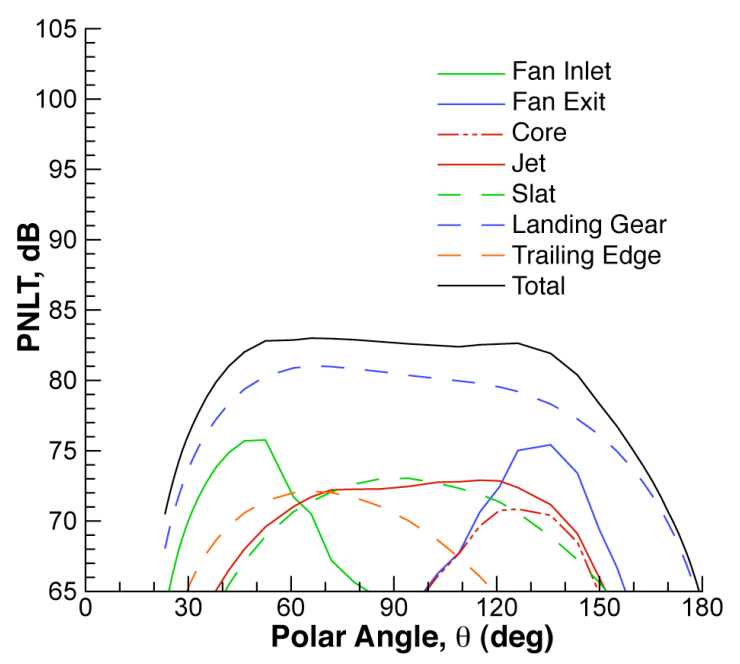

d) HWB C7 Approach

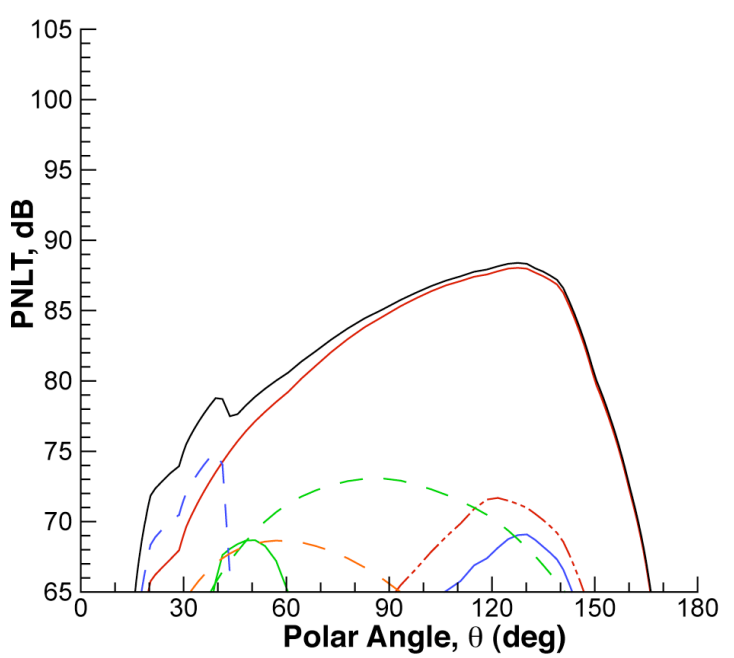

e) HWB C7 Sideline

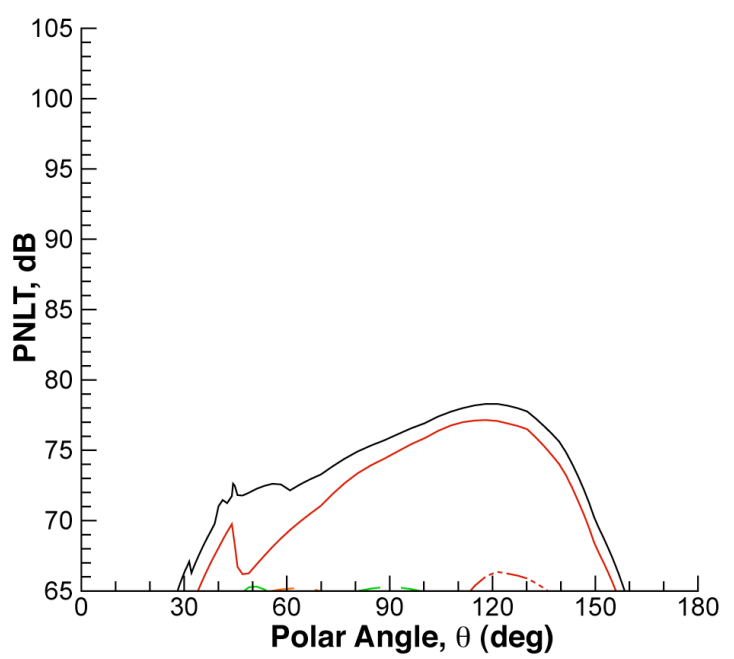

f) HWB C7 Cutback

Figure 19. Tone-corrected perceived noise level, PNLT, as a function of flyover angle (observer at 90 degrees) at approach, sideline and cutback conditions for Configuration 1 (a, b, and c) and 7 (d, e, and f). 


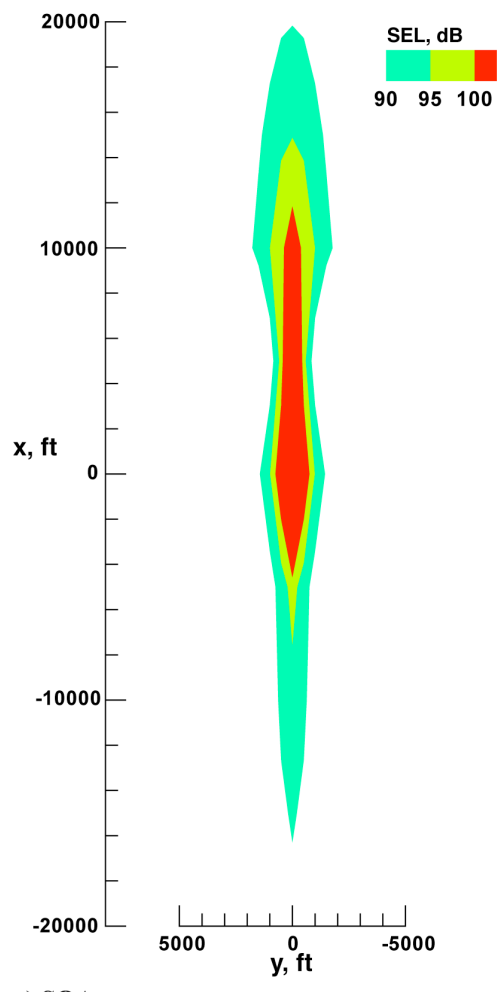

a) $\mathrm{SOA}$
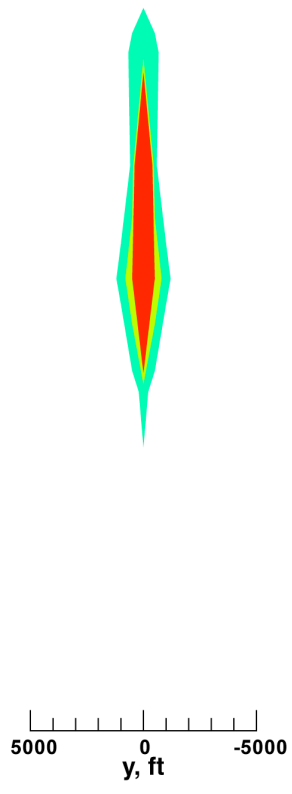

b) HWB C7

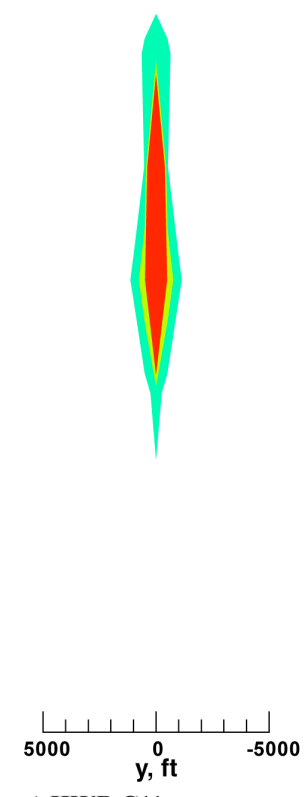

c) HWB C11

Figure 20. Sound exposure level (SEL) ground contours for a simulated landing and takeoff for a) SOA aircraft, b) HWB Best with C7 and, c) HWB Best with C11.

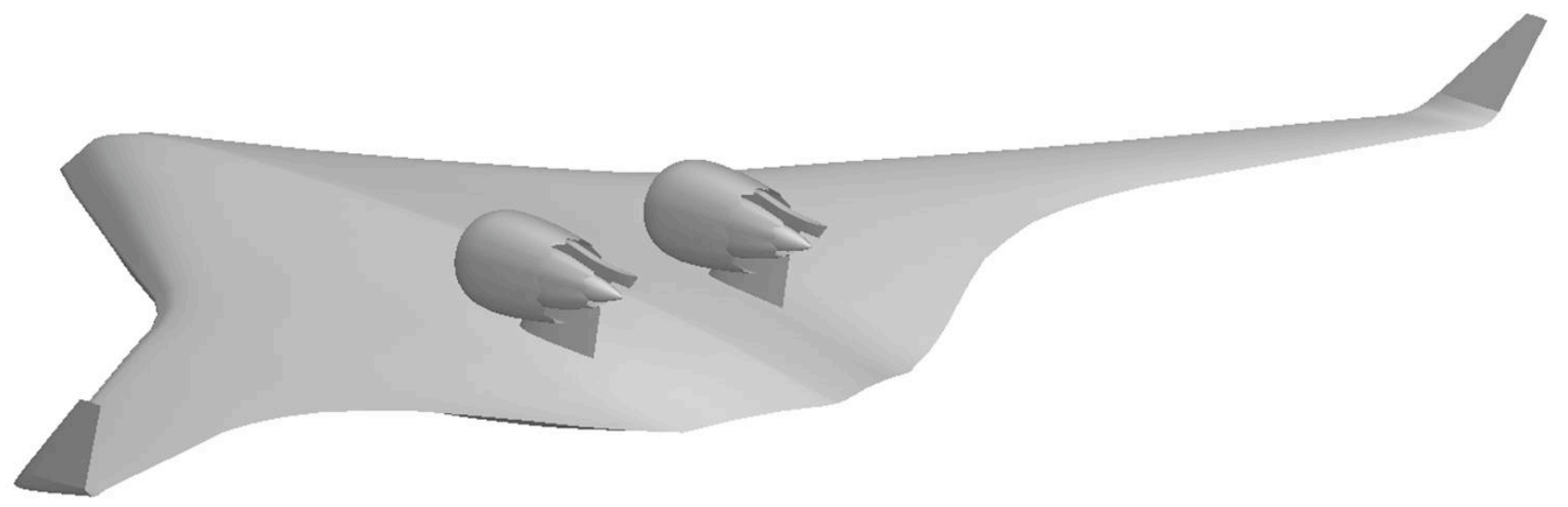

Figure 21. Lowest noise HWB configuration (quiet landing gear not shown) recommended based on the results of this study. 